\title{
Thin Film Growth Through Sputtering Technique and Its Applications
}

\author{
Edgar Alfonso, Jairo Olaya and Gloria Cubillos \\ Universidad Nacional de Colombia \\ Colombia
}

\section{Introduction}

During the last decade the dc and rf sputtering techniques have been used extensively in their two configurations - balanced and unbalanced magnetron. The main applications have been in the fields of industry and research. Examples of industrial applications are: decorative thin films (Raymond \& Baham, 1999), hard wear-resistant thin films (Rodil \& Olaya, 2006), low-friction thin films (Heimberg et al., 2001) corrosion-resistant thin films (Flores et al., 2006), and thin films used as a protective optical system (Stefan et al., 2008), as well as maybe the most interesting applications, thin films used in the electronic industry (Monroy et al., 2011). In the research field, the investigation has been oriented toward understanding the main physical mechanisms, such as: interaction between charged particles and the surface of the target material, adherence between the substrate and the deposited material, and chemical reactions near the substrate, as well as the influence of the deposit parameters (substrate temperature, working pressure, density power applied to the target). This research has produced thin films with a high degree of crystallinity and with the possibility of various industrial applications.

Moreover, researchers have made an effort to improve the system of operation. These efforts have been initiated through the so-called conventional or balanced magnetron sputtering in the early 1970s (Waits R, 1978), followed by the development of unbalanced systems in the late 1980s (Window, 1986) and its incorporation into multi-source "closed-field" systems in the early 1990s (Teer, 1989). Finally, the sputtering technique can increase the rate of deposition and ion energy by applying a unipolar high power pulse of low frequency and low duty cycle to the cathode target, referred to as high-power impulse magnetron sputtering (HiPIMS) or high-power pulsed magnetron sputtering (HPPMS). Common to all highly ionized techniques is very high density plasma. Implementing these discharges in sputter deposition technology modifies the surface of components, bringing improvements in mechanical, chemical, optical, electronic, and many other properties of the material. Highcurrent glows are transient discharges operating at simultaneously high voltage $(>300 \mathrm{~V})$ and high current density $\left(>100 \mathrm{mAcm}^{-2}\right)$. They have recently proven successful for the deposition of thin-film materials. These developments have made it possible to have an exceptionally versatile technique, suitable for the deposition of high-quality, well-adhered films of a wide range of materials with high rates of deposition. Table 1 show the main applications obtained in the last decade with the magnetron sputtering (balanced and unbalanced) $\mathrm{rf}$ and dc versions. 


\begin{tabular}{|l|l|l|}
\hline \multicolumn{1}{|c|}{ Technique } & \multicolumn{1}{|c|}{ Coating } & \multicolumn{1}{c|}{ Reference } \\
\hline Balanced magnetron & $\begin{array}{l}\text { Nano-composites of NC- } \\
\text { TiC wear applications }\end{array}$ & (Pavel, et al., 2011) \\
\hline Balanced magnetron & $\begin{array}{l}\text { Optical properties of AlSiN } \\
\text { nano-composites }\end{array}$ & (Liu, et al., 2009) \\
\hline Balanced magnetron & $\begin{array}{l}\text { Hard coatings to decorative } \\
\text { applications }\end{array}$ & (Raymond \& Baham, 1999) \\
\hline Balanced magnetron & $\begin{array}{l}\text { Nd-Fe-B Film for magnetic } \\
\text { applications }\end{array}$ & (Liu, et al., 20007) \\
\hline Balanced magnetron & Optical applications. & (Stefan, et al., 2008) \\
\hline Unbalanced magnetron & $\begin{array}{l}\text { Hard films for corrosion } \\
\text { and wear applications }\end{array}$ & (Rodil \& Olaya, 2006). \\
\hline Unbalanced magnetron & $\begin{array}{l}\text { Nb Films for biological } \\
\text { applications }\end{array}$ & (Olivares, et al.,2011) \\
\hline Unbalanced magnetron & $\begin{array}{l}\text { NbO films for biological } \\
\text { applications }\end{array}$ & (Ramirez, et al., 2011) \\
\hline Unbalanced magnetron & $\begin{array}{l}\text { Electrical applications of } \\
\text { NbN films. }\end{array}$ & ( Olaya, et al., 2008,) \\
\hline Unbalanced magnetron & $\begin{array}{l}\text { Diamond-like carbon films } \\
\text { for infrared transmission } \\
\text { enhancement }\end{array}$ & (Lingxia \& Xu, 2000). \\
\hline $\begin{array}{l}\text { High power pulsed } \\
\text { magnetron sputtering }\end{array}$ & $\begin{array}{l}\text { Thin films for automotive } \\
\text { engineering }\end{array}$ & (Bewilogua, et al., 2009) \\
\hline $\begin{array}{l}\text { High power pulsed } \\
\text { magnetron sputtering }\end{array}$ & $\begin{array}{l}\text { TiAlCN/VCN films for } \\
\text { tribological applications }\end{array}$ & (Kamath, et al., 2011) \\
\hline
\end{tabular}

Table 1. Technological applications of thin films obtained with magnetron sputtering

In sputtering there are two means of operation: $\mathrm{dc}$ (diode and triode) and ac (radiofrequency), which also function in two configurations: magnetron dc (balanced and unbalanced) and magnetron ac (balanced and unbalanced).

In dc (diode) discharge, the cathode electrode is the sputtering target and the substrate is placed on the anode, which is often at ground potential (Vossen \&Cuomo, 1978). The applied potential appears across a region very near the cathode, and the plasma generation region is near the cathode surface. The cathode in dc discharge must be an electrical conductor, since an insulating surface will develop a surface charge that will prevent ion bombardment of the surface. This condition implies that dc sputtering must be used to sputter simple electrically conductive materials such as metals, although the process is rather slow and expensive compared to vacuum deposition. An advantage of dc sputtering is that the plasma can be established uniformly over a large area, so that a solid large-area vaporization source can be established.

On the other hand, in dc sputtering the electrons that are ejected from the cathode are accelerated away from the cathode and are not efficiently used for sustaining the discharge. To avoid this effect, a magnetic field is added to the dc sputtering system that can deflect the electrons to near the target surface, and with appropriate arrangement of the magnets, the 
electrons can be made to circulate on a closed path on the target surface. This high current of electrons creates high-density plasma, from which ions can be extracted to sputter the target material, producing a magnetron sputter configuration (Penfold, 1995). A disadvantage of the magnetron sputtering configuration is that the plasma is confined near the cathode and is not available to active reactive gases in the plasma near the substrate for reactive sputter deposition. This difficulty can be overcome using an unbalanced magnetron configuration (see Fig. 1), where the magnetic field is such that some electrons can escape from the cathode region (Windows \& Savvides, 1986). A disadvantage of the unbalanced magnetron is that the current of escaping electrons is not uniform, and the plasma generated is not uniform.

In ac sputtering, working at frequencies below about $50 \mathrm{kHz}$, the potential on the target is periodically reversed, and the ions have enough mobility so that a dc diode-like discharge, where the total potential drop is near the cathode, can be formed alternately on each electrode. The substrate chamber walls can be used as the counterelectrode. At frequencies above $50 \mathrm{kHz}$, the ions do not have enough mobility to allow establishing a dc-diode-like discharge and the applied potential is felt throughout the space between electrodes. The electrons acquire sufficient energy to cause ionizing collisions in the space between the electrodes. When an rf potential with a large peak-to-peak voltage is capacitively coupled to an electrode, an alternating positive-negative potential appears on the surface. During part of each half-cycle, the potential is such that ions are accelerated to the surface with enough energy to cause sputtering, while in alternate half-cycles, electrons reach the surface and prevent any charge buildup. Rf sputtering can be used to sputter insulating material, although the sputtering rate is low. A major disadvantage of rf sputtering of dielectric targets is that most insulating materials have poor thermal conductivity and high coefficients of thermal expansion, and are usually brittle materials. Since most of the bombarding energy produces heat, this means that large thermal gradients can be generated that result in fracturing the target if high power levels are used.

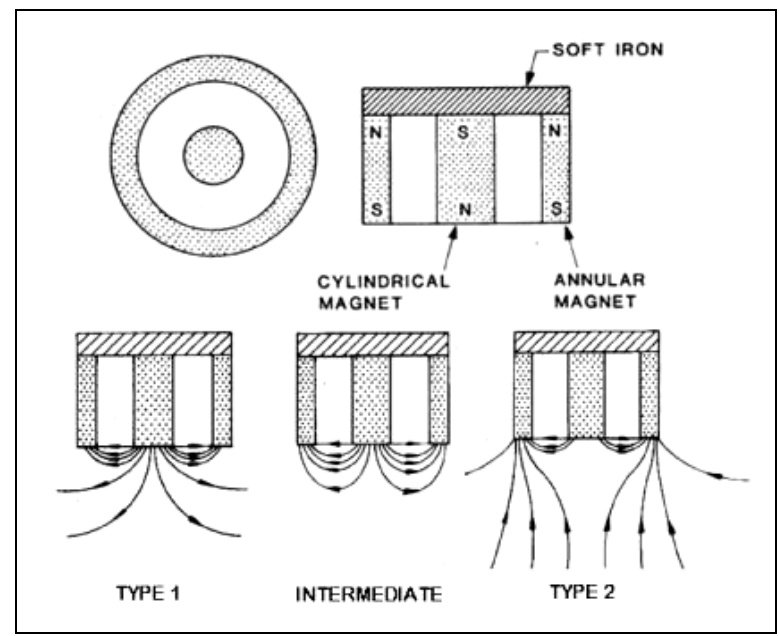

Fig. 1. Schematic configuration of the a- balanced magnetron (intermediate) and bunbalanced magnetron (type 1and type 2 ( B. Window \& N. Savvides, 1986) 
Rf sputtering can be used with a magnetic field in balanced and unbalanced configurations to obtain a result similar to dc-like diode discharge. In fig 2 the different configurations of dc and rf sputtering are shown.

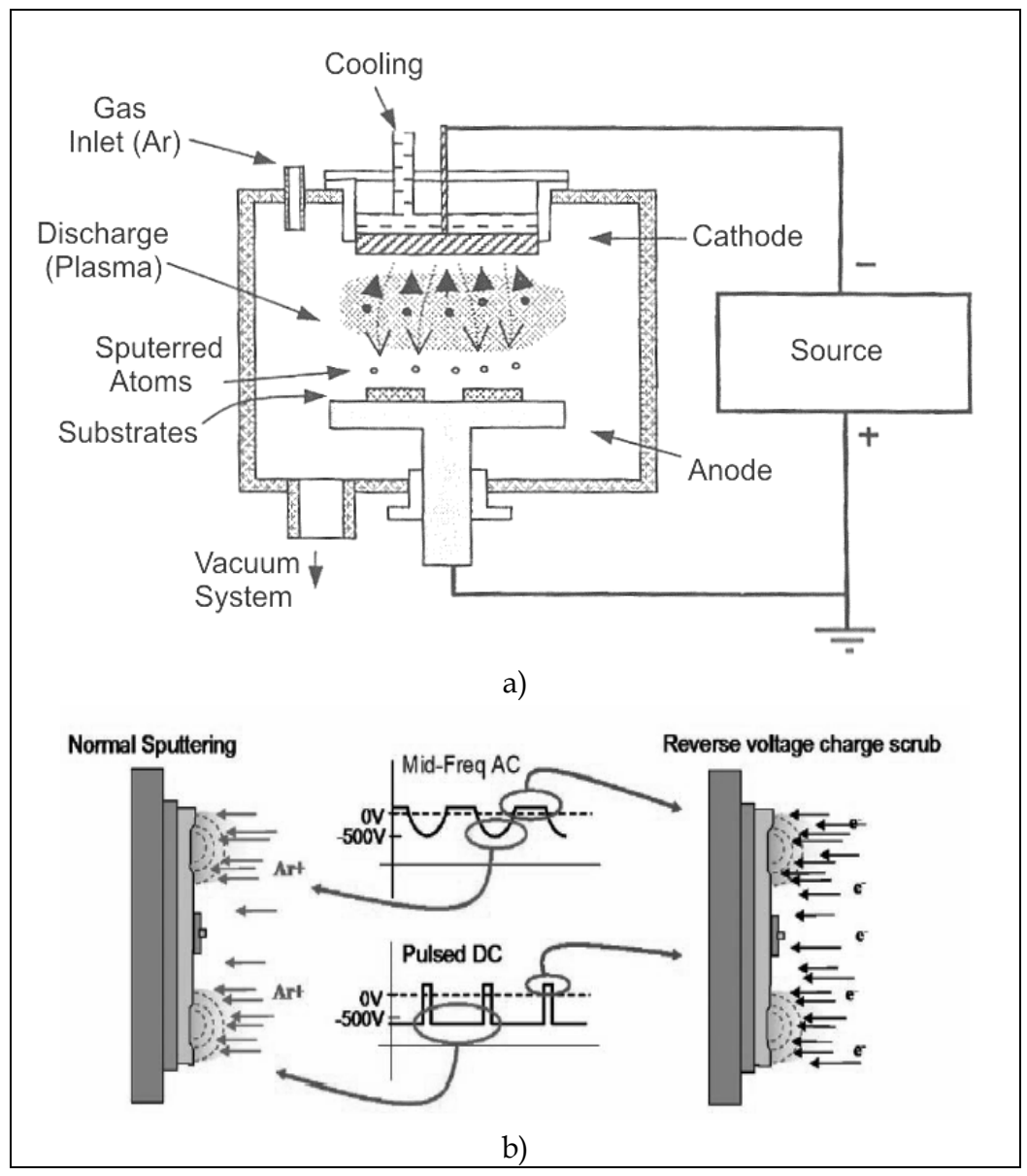

Fig. 2. Sputtering configurations a) dc sputtering, b) rf sputtering

It is important to state that in all the cases discussed above, the target and the substrate were facing (on- axis sputtering). In this configuration, the highly energetic electrons irradiate the substrates and/or the growing surface of the thin films during deposition. Off-axis sputtering reduces the effects of the irradiation of the high-energy particles. In off-axis sputtering, the substrates are settled at the outside of the discharge plasma. The thickness distribution of thin films deposited by off-axis sputtering will be larger than that for on-axis sputtering. A rotating substrate holder with a metal shadow mask is used for the reduction of the thickness distribution of the off-axis sputtering. Under a suitable design, the thickness distribution is less than $2 \%$ for substrates of $100 \times 100 \mathrm{~mm}$ in an rf sputtering system using a 5-inch target (Shibahara et al., 1987). 
In this chapter we will present the physical parameters involved in the growth of thin films; also discussed will be the influence that the growth parameters have on the degree crystallinity of the films, the chemical characterization, and the optical characterization of the films; and finally, we will discuss the residual stress, hardness, and corrosion and wear resistance of thin films.

\section{Physical sputtering}

The main physical phenomenon involved in the sputtering technique is the momentum transfer between energetic atomic-sized particles (usually ions of noble gases) and the atoms of the surface of the material (target). During the interchange of momentum, many effects can be produced on the elastic and inelastic collisions; in the first kind of collision, mainly reflected particles can be found (neutrals, ions of the target and the gas). In the second kind, the collisions can present secondary electrons, UV/visible photons, X-ray and implanted particles; schematically, Fig. 3 shows different processes that may occur during the interaction between charged particles and the surface of the material.

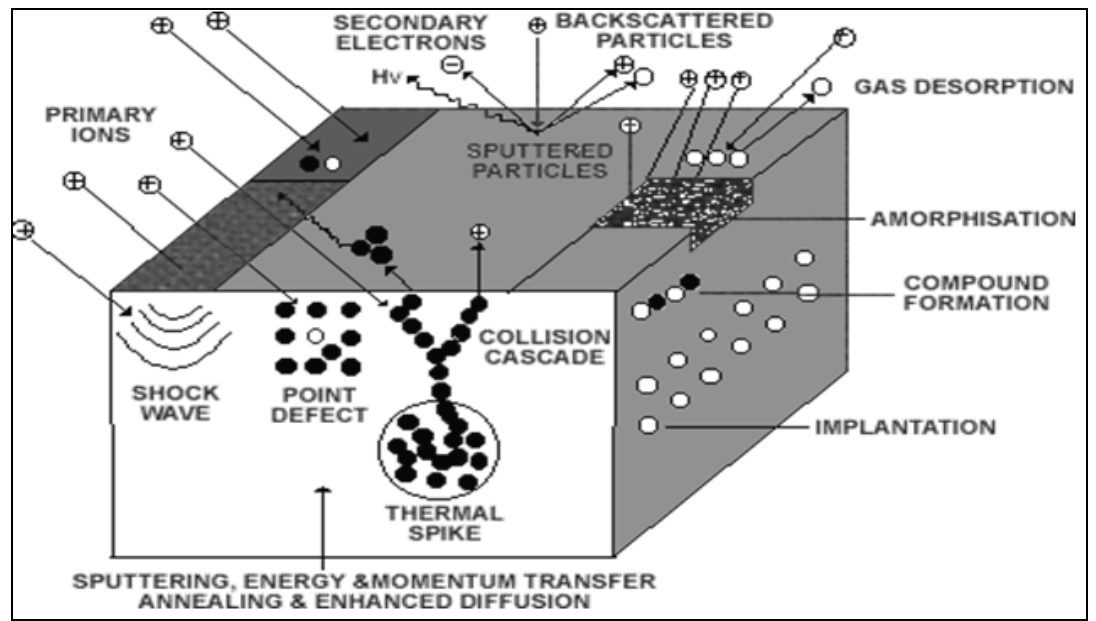

Fig. 3. The main physical process produced in sputtering technique (Weissmantel, 1983).

The momentum-transfer theory for physical sputtering was proposed early on, but was replaced by the "hot-spot" theory, in which the process of thermal vaporization is involved. The confusion about the physical process present in sputtering has only been overcome thanks to the work of Gunthersshulze in the 1920's and 30's and Wehner et al. in the 1950's and 60's, who demonstrated that the effects produced in sputtering could only be explained by the momentum transfer theory. These effects can be summarized as:

1. The sputtering yield (ratio of atoms sputtered to the number of high-energy incident particles) depends on the mass of the bombarding particle as well as their energy. For ion energies from $100 \mathrm{eV}$ to $1000 \mathrm{eV}$ the sputtering yield can be calculated as:

$$
Y=\frac{3 \alpha}{4 \pi^{2}} \frac{4 m_{1} m_{t}}{\left(m_{1}+m_{t}\right)^{2}} \frac{E}{U}
$$


where $\mathrm{m}_{\mathrm{i}}$ is the atomic mass of the bombarding incident ion, $\mathrm{m}_{\mathrm{t}}$ the atomic mass of the target, $\mathrm{U}$ the binding energy of the surface atom of the target, E the energy of the incident ion, and $\alpha$ depends on the ratio of the masses of the target atom and the incident ion (monotonically increased with $\mathrm{mi} / \mathrm{m}_{\mathrm{t}}$; for a ratio $0.1 \alpha=0.17$ for a ratio $10 \alpha=1.4$ ) (Ochiati, 1986).

The sputtering yield is sensitive to the angle-of-incidence of the bombarding particle.There is a "threshold energy" below which sputtering does not occur no matter how high the bombarding flow.

2. Many sputtering atoms have kinetic energies much higher than those of thermally evaporated atoms.

3. Atoms ejected from single crystals tend to be ejected along the directions of the closepacked planes in the crystal.

4. In a polycrystalline material, some crystallographic planes are sputtered faster than are others.

5. Atoms sputtered from the alloy's surface are deposited in the ratio of the bulk composition, not their relative vapor pressure, as in the case of thermal vaporization.

6. Sputtering yields decrease at very high energies because the ions lose much of their energy far below the surface.

7. The sputtering yield is rather intensive to the temperature of the sputtering target.

8. There is no sputtering by electrons even at very high temperature.

9. The secondary electron emission by ion bombardment is low, whereas high rates from thermo electron emission would be expected if high temperatures were present.

Effects 1 through 7 above are important for the growth of films by sputter deposition. This is particularly true for low pressure $(<5 \mathrm{~m}$ Torr $)$.

\section{Physical models that explain the microstructure of thin film growth through sputtering}

The microstructure of thin films is related to the mobility of the adatoms during growth. The energy supply to the atoms is provided by the following mechanism: a- thermal effect, bionic bombarding and c- chemical reactions at the substrate. The effects that are produced by these mechanisms in the growth of thin films can be explained by the structure zone model (SZM). The SZM model can determine the morphology and microstructure of the films as a function of the adatoms, regardless of the kind of material. The parameters that the SZM model includes for determining the microstructure of the films are basically the substrate temperature, the final working pressure, the bias voltage applied to the substrate, and the thermal characteristics of the target. For example, in the research of Movchan and Demchishin (Movchan \& Demchisshim, 1969), it has been established that the microstructure of the thin films of $\mathrm{Ti}, \mathrm{Ni}, \mathrm{ZrO}_{2}$ y $\mathrm{Al}_{2} \mathrm{O}_{3}$ is related to the normalized temperature, i. e. Ts/Tm (Ts is the temperature of the substrate and $\mathrm{Tm}$ is the melting temperature of the target). Movchan et al. have shown that in metallic films there are three well-defined zones.

The first zone is $\mathrm{Ts} / \mathrm{Tm}<0.3$. This zone is formed by small and elongated grains that form a columnar structure with porous morphology and weakly binding grains. The columnar structure is produced by a low diffusion, a low mobility of the atoms adsorbed by the substrate surface, and the atomic shadow effects, which are produced by varying velocity in 
the growth the columns and the various incidence angles at which the atoms arrive at the surface of the substrate. In the second zone, $0.3 \leq \mathrm{Ts} / \mathrm{Tm} \leq 0.45$, the substrate temperature increasing homogeneous which leads to a higher diffusion of the adatoms, which produce a dense structure with a higher degree of binding among the columns and the borders between columns, with borders of the grain beginning to form. In this zone, the size of the grain can be increased and the grains extended in equiaxed form, from interface substratefilm to film surface. In the third zone, Ts $/ \mathrm{Tm}>0.45$, the volumetric diffusion size has a great influence on the morphology of the film, due to the increase in the diffusion into the grains, which produces growth of the grains, formation of the equiaxed grain and re-crystallization. These effects produce a greater crystalline structure.

Thorton (Thorton, 1974) elaborated the zone classification, considering the final working pressure, because this growth parameter can change both the kinetic energy of the ions that arrive at the substrate and the mean free path of the particles, which allows an increase or decrease in the bombardment of the surface of the substrate, which in turn determines the mobility the adatoms in that surface. In the Thorton model, the T zone as a transitional zone between first and second zone discussed above was added. The T zone is formed by grains defined by the limits of the low porosity. The surfaces of the T zone are denser and less rough than the two surfaces around them (see fig 4).

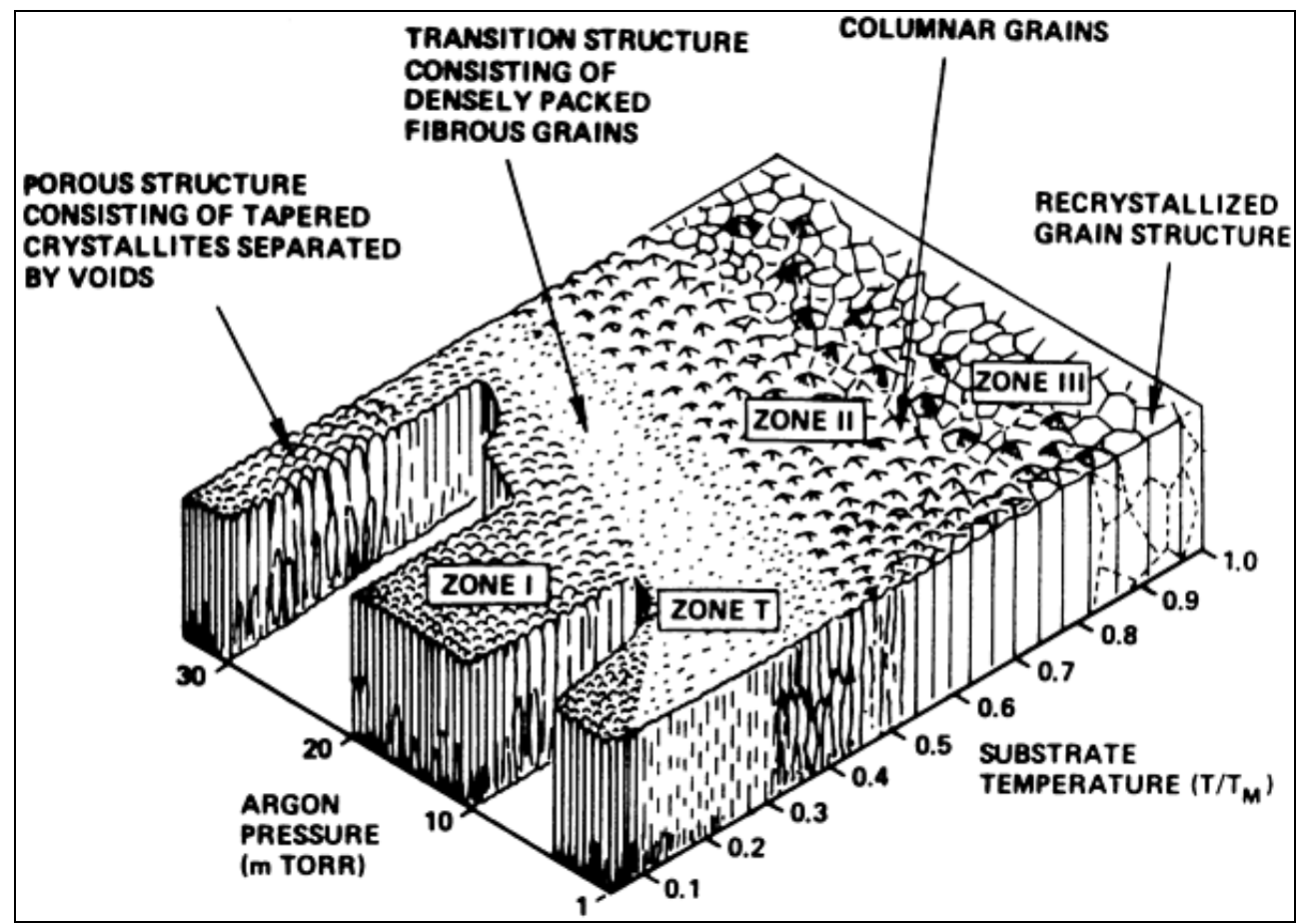

Fig. 4. Thorton zone model (Thonton, 1974)

Moreover, Messier (Messier \& Giri, 1984) found that in thin films of $\mathrm{TiB}_{2}, \mathrm{BN}$ and $\mathrm{SiC}$ there is a non-linear limit between the first zone and $\mathrm{T}$ zone, which is a function of the bias 
voltage applied to the substrate. The bias voltage of the substrate has the same effect on the mobility and adsorption of the atoms as an increase in the temperature, so when it is increased, the $\mathrm{T}$ zone increases and the first zone decreases, resulting in denser thin films and with a high degree of crystallinity.

The bias voltage also influences the mechanical properties of thin films; for example, with a voltage $(\geq 100 \mathrm{~V})$ applied to the substrate, the deformation of the lattice increases, causing high residual efforts and low adherence between the substrate and the film.

A new three-dimensional SZM model has been produced in order to explain the simultaneous influence of the normalized temperature, the bias voltage, and the relation between ion density current $\left(\mathrm{J}_{\mathrm{i}}\right)$ and density deposited atoms $\left(\mathrm{J}_{\mathrm{a}}\right)$. In Fig. 5, it can observed that it is possible to obtain the third zone with high density using a combination highdensity ionic current, intermediate values of normalized temperature, and low bias voltage (Kelly \& Arnell, 1998).

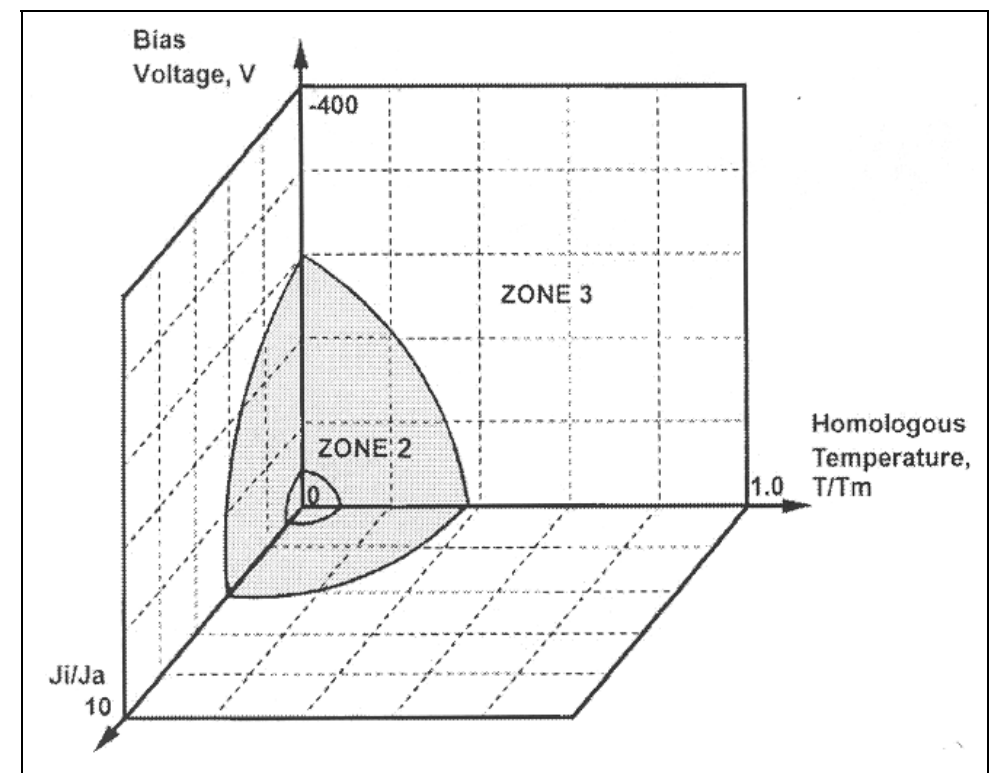

Fig. 5. The zone model including the relation between current density of ions and current density of atoms (Kelly \& Arnell, 1999).

Other parameters of growth that affect the microstructure are the power supply to the target and gas flows. For example, changing the nitrogen flow during the growth of TiN and $\mathrm{NbN}$ films changes the preferred orientation of the films from the [111] direction to the [200] direction (Alfonso et al., 2010). Explaining the change in the direction of growth of metallic nitride films is a very complex procedure, as is shown in table 2, where it can be observed that any parameter change can influence the direction of growth of the film. There are three models that explain the preferential growth direction: a) the thermodynamic model (Pelleg et. al., 1991); b) the kinetic model (Greene et al., 1995), and c) the atomic model (Petrov et al., 2003). 


\begin{tabular}{|c|c|c|c|}
\hline Material & Parameter & Change of orientation & References \\
\hline \multirow[t]{6}{*}{$\mathrm{TiN}$} & $\mathrm{Ji} / \mathrm{Ja}$ & $(111) \rightarrow(200)$ & (Green et al., 1995) \\
\hline & $\mathrm{N} 2 / \mathrm{Ar}$ & $(111) \rightarrow(200)$ & (Noda et al., 2002) \\
\hline & $\mathrm{Th}$ & Mixed $\rightarrow(200) \rightarrow(111)$ & (Pelleg et al., 1991) \\
\hline & $\mathrm{Vb}$ & $(200) \rightarrow(111) \rightarrow(220)$ & $\begin{array}{c}\text { (Kobayashi \& Doy, } \\
\text { 1984) }\end{array}$ \\
\hline & $W$ & $(200) \rightarrow(111)$ & (Je et al., 1997). \\
\hline & $\mathrm{T}$ & $(111) \rightarrow(200)$ & (Cheng et al., 2002) \\
\hline \multirow[t]{6}{*}{ AlN } & $\mathrm{P}$ & axis $c \rightarrow$ axis a & (Lee \& Y. Lee, 1994) \\
\hline & ds-t & axis $\mathrm{c} \rightarrow$ axis a & (Ishihara et al., 1998) \\
\hline & $\lambda / \mathrm{ds}-\mathrm{t}$ & axis $\mathrm{a} \rightarrow$ axis $\mathrm{c}$ & (Ishihara et al., 1998) \\
\hline & $\mathrm{N} 2 / \mathrm{Ar}$ & axis $\mathrm{a} \rightarrow$ axis $\mathrm{c}$ & (Lee \& Y. Lee, 1994) \\
\hline & $\mathrm{Vb}$ & axis $\mathrm{a} \rightarrow$ axis $\mathrm{c} \rightarrow$ axis a & $\begin{array}{c}\text { (Wang \& Zhao, } \\
\text { 1997). }\end{array}$ \\
\hline & W & axis $\mathrm{a} \rightarrow$ axis $\mathrm{c}$ & (Lee \& Y. Lee, 1994) \\
\hline \multirow[t]{3}{*}{$\mathrm{TaN}$} & $\mathrm{N} 2 / \mathrm{Ar}$ & $(111) \rightarrow(200) \rightarrow(111)$ & (Nie et al., 2001) \\
\hline & $\mathrm{Vb}$ & $(111) \rightarrow(220)$ & (Lin \& Lee, 2000) \\
\hline & $\mathrm{Ji} / \mathrm{Ja}$ & $(111) \rightarrow(200)$ & (Shi et al., 2002) \\
\hline
\end{tabular}

Table 2. Relationship between the deposition parameters and film preferential orientation. Ji/Ja: ion-atom flow ratio, $\mathrm{N}_{2}$ / Ar: flow ratios, $\mathrm{t}$ h: thickness, $\mathrm{Vb}$ : bias voltage, $\mathrm{W}$ : power supply, Ts: substrate temperature, P: pressure, ds-t: target-substrate distance $y \lambda$ : free mean path.

In the thermodynamic model, it has been established that the growth orientation in thin films is produced at the thermodynamic equilibrium, which it reaches when the total energy $\left(\mathrm{W}_{\mathrm{hkl}}\right)$ of the system substrate-film is at a minimum. In this case, $\mathrm{W}_{\mathrm{hkl}}$ is formed by the addition of surface energy $\left(S_{h k l}\right)$ and deformation energy $\left(U_{h k l}\right), S_{h k}$ passivation; energy is produced by unsaturated bonding at the surface. $S_{\mathrm{hkl}}$ can be calculated by:

$$
S_{h k l}=\frac{\Delta H N_{h k l}}{Z}\left\lfloor\frac{J}{m^{2}}\right\rfloor
$$

where $\Delta \mathrm{H}$ is the sublimation energy, $\mathrm{N}_{\mathrm{hkl}}$ is the number of unsaturated bondings per atom at the plane (hkl), and $\mathrm{Z}$ is the amount of coordination among neighbors. Equation 2 does not include impurities.

On the other hand, deformation energy is related to intrinsic efforts in the film. Considering only two dimensions, $\mathrm{U}_{\mathrm{hkl}}$ can be calculated by:

$$
U_{h k l}=\epsilon_{h k l}^{2} E_{h k l}(1-\mu)
$$

where $\varepsilon_{\mathrm{hkl}}$ is the deformation along the plane (hkl) of the film, $E_{\mathrm{hkl}}$ is the elastic module of the plane (hkl), and $\mu$ is the Poisson ratio. Research has established that the values of $\varepsilon_{\mathrm{hkl}}$ and $E_{\text {hkl }}$ are different for (111), (220) and (200) planes (Ma et al., 2004), and using equations (2) and (3) an order relation has been obtained: $S_{111}>S_{220}>S_{200}$ and $U_{200}>U_{220}>U_{111}$. These 
relations imply that the preferential orientation is determined by a configuration of minimum total energy, which results in competition between the (111), with minimum deformation energy, and (200) planes, with minimum surface energy.

Moreover, Pelleg has researched the variation of the total energy ( $\left.\mathrm{W}_{\mathrm{hkl}}\right)$ for the (111), (220) and (200) planes as a function of the thickness of the TiN film deposited at 373K through the rf sputtering technique. These results have shown that the surface energy does not change with the thickness, the deformation energy increases proportionally with the thickness, and the slope of the straight line represents the deformation per volume.

In the kinetic model, it is proposed that the kinetic process of the ions is involved in the orientation of the growth, which influences the surface substrate, the energy and flow of the ions being the main parameters. A thin film grows in the [111] direction because the adatoms have limited mobility, caused by the low temperature of the substrate and the restricted flow of the ions. Increasing the mobility, either through increasing the substrate temperature or raising the relation $\mathrm{J}_{\mathrm{i}} / \mathrm{J}_{\mathrm{a}}$ above five, a preferential orientation in the [200] direction is obtained.

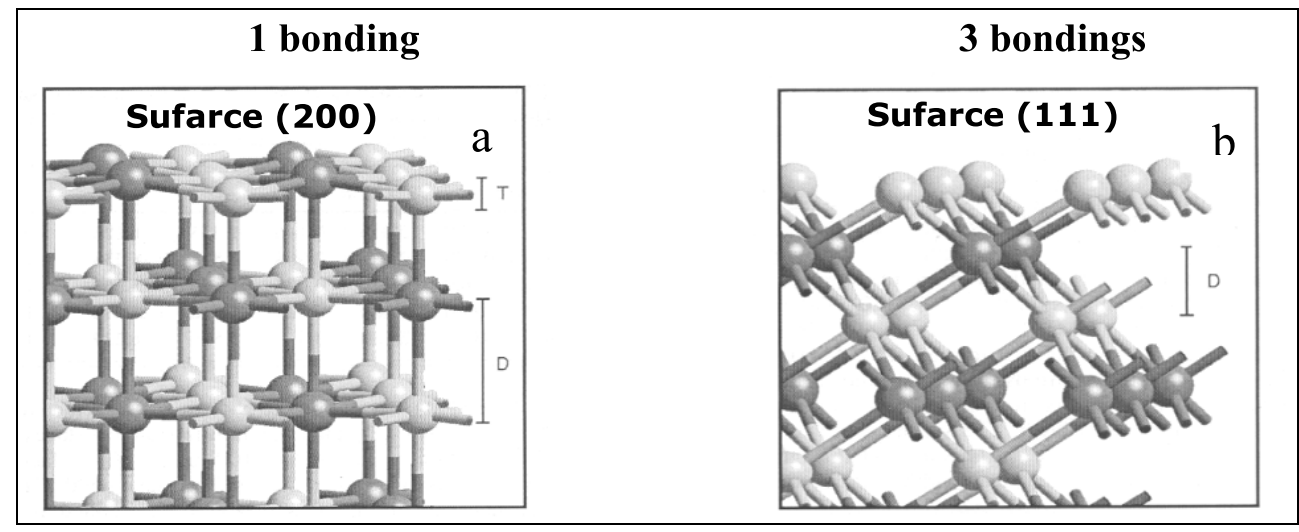

Fig. 6. Surface growth on a- (200) planes and b- (111) planes. The growth on the (200) plane has 1 binding, while the surfaces grown on (111) planes have 3 bandings (M. Marlo \& V. Milman, 2000).

Finally, the atomistic model considers that in thin films deposited at high temperatures the thermodynamic parameters control the orientation of the growth, favoring planes with low energy, i.e. the (200) planes. This behavior can be understood if adatoms with low diffusion, as in the case of the cation $\mathrm{Cl}$ in $\mathrm{NaCl}$, which have three bonds in the (111) surface, and have high diffusion in surface (200), are considered to have only one bond (see Fig. 6), leading to the conclusion that if $\mathrm{NaCl}$ thin films are grown at high temperatures, they probably will grow along the [200] direction.

On the other hand, the same model establishes that the degree of ion bombardment is influenced by the flow ratio between the density current of the ions and the density current of the atoms, Ji/Ja, and the ion energy, $\mathrm{Ei}$, and both depend on the pressure, substrate target distance, and substrate bias (Ensinger, 1998; Losbichle \& Mitterer, 1997). One parameter that combines both the ion energy and the flow has been suggested by Musil and Kadlec (Musil 
\& Kadlec, 1990), Ziemann and Kay for Pd coatings (Ziemann and Kay, 1993) and passivation for CBN films (Kulisch, et al.,1999). This represents the energy deposited per dense particle. This bombardment-induced mobility parameter, known as the energy parameter Ep, is defined as:

$$
E_{p}=\frac{J_{i}}{J_{a}} \times E_{i}
$$

where $E_{i}$ is incident energy of the ions and is obtained from the plasma potential $\left(V_{p}\right)$ and substrate bias $\left(\mathrm{V}_{s}\right)$ and the elementary charge by the expression $E_{i}=e\left(V_{s}-V_{p}\right)$.

\subsection{Physical mechanisms of thin film growth}

So far, we have studied the influence of the growth parameters on the structure and microstructure of thin films; now we discuss the main physical mechanisms involved in the nucleation and crystallization of the films over the substrate. Studies done through Xray diffraction, optical diffraction and mainly through electron diffraction have allowed establishing that there are three mechanisms of the nucleation and growth of thin films, which depend on the thermodynamic parameters of the deposit and the substrate surface interaction between the adatoms and the substrate material (Green, 1994). The three basic modes are: (i) Volmer-Weber model, (ii) Frank-Van der Merwe model and (iii) StranskiKrastanov model. A schematic illustration of each of these modes of growth is shown in Fig. 7.

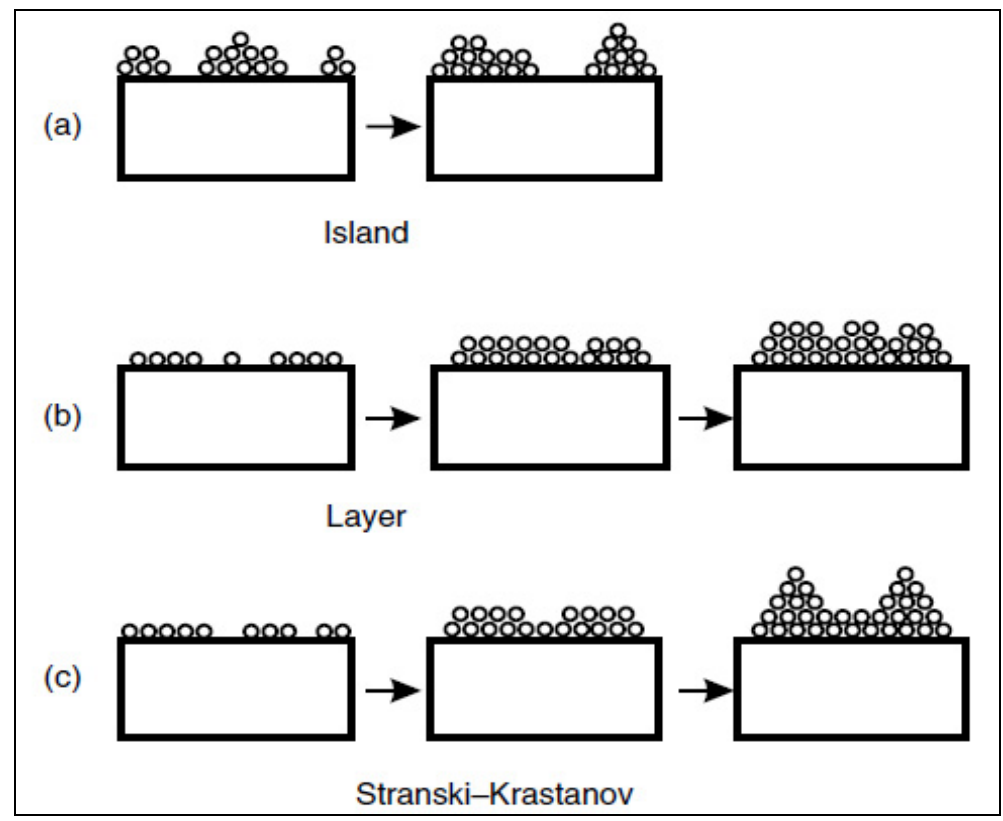

Fig. 7. Modes of growth of film: a- Volmer-Weber island growth b- Frank-vander Merwe layer growth and c- Stranski-Krastanov layer plus island growth (Harsha, 2005). 
In the Volmer-Weber model, equilibrium exists in a three-dimensional crystal of the film in contact with the substrate, while the rest of the substrate is devoid of any condensed phase. Nucleation of film occurs in the form of discrete three-dimensional nuclei on the surface of the substrate, for example lead on graphite. Both the number of nuclei and the size of a given nucleus increase. Finally, the nuclei grow in size until they intersperse with each other to form a continuous film.

In the Frank and Vander Merwe model, nucleation occurs in the form of a monolayer island of the deposit. Eventually the monolayer's grow together to form a complete continuous monolayer of the deposit. The process repeats itself so that the deposit grows in a layer-bylayer manner, for example rare gases on graphite. In this growth, the interaction between the substrate and the layer atoms is stronger than that between neighboring layer atoms. Layer-by-layer growth is hindered by elastic constraints at the solid-solid interface.

The Stransky and Krastanov (S-K) model combines the features of layer-by-layer growth and discrete three-dimensional nucleation The S-K nucleation is common with metal-onmetal deposition and at low temperatures where the surface mobility is low (Greene, 1987). The conditions for these types of growth are generally described in terms of thermodynamics and surface energy considerations. In this model, nucleation and growth occurs as in the layer-by-layer mode, so that a finite number of monolayer's is produced. Subsequent formation of film occurs by formation of discrete nuclei. The lattice mismatch between the substrate and the deposit cannot be accommodated when the layer thickness increases, so the three-dimensional growth follows the layer-by-layer growth. Alternatively, symmetry or orientation of the overlayers with respect to the substrate might be responsible for the production of this growth mode.

The foregoing models were summarized by Barna and Adamik (Barna \& Adamimik, 1998), who established that the growth of the films has the following evolution: nucleation, island growth, coalescence of islands, formation of polycrystalline islands and channels, development of continuous structure, and thickness growth.

According to Barna, the nucleation starting the growth of individual islands takes place on the substrate surface at the very first stage of the condensation (primary nucleation) or later on the bare substrate surface area developing upon liquid-like coalescence ( secondary nucleation). A peculiar case of nucleation shows up on the surface of a growing crystal when its growth is blocked by a surface covering layer (SCL) of an impurity phase. This is the repeated nucleation. The primary nucleation starts the condensation and the film growth on the whole substrate surface simultaneously, while the secondary and the repeated nucleation initiates the start of the growth locally in later stages of film formation. It is important to note that on amorphous substrates the nuclei are randomly oriented.

Crystal growth is the fundamental structure-forming phenomenon which incorporates the depositing material into the condensed phase. Two main cases of crystal growth should be considered in the case of polycrystalline thin films: a- the growth of discrete crystals dispersed on the substrate surface, (Fig. $8 a$ and b), and b- the growth of crystals which are parts of a polycrystalline structure (Fig. 8c and d). Crystals growing from the nuclei are randomly oriented due to the random orientation of the nuclei. The complete coalescence of the crystals touching each other produces a grain coarsening, resulting also in the development of discrete single crystals and is connected to some changes in the orientation controlled mainly by the minimization of the substrate-crystal interface energy. The 
intersection lines of the crystal side faces and the substrate present a specific structural precondition for the growth of these crystals. The intersection lines can be active or passive in the monolayer nucleation on the side crystal faces. In the first case, the movement of the monolayer growth steps proceeds from the intersection line to the top of the crystal, while in the second case, the movement of the growth steps proceeds in the direction of the intersection line. In the presence of impurities, the direction of the movement of the growth steps will be important in determining the location of the developing second phase, e.g., SCL.

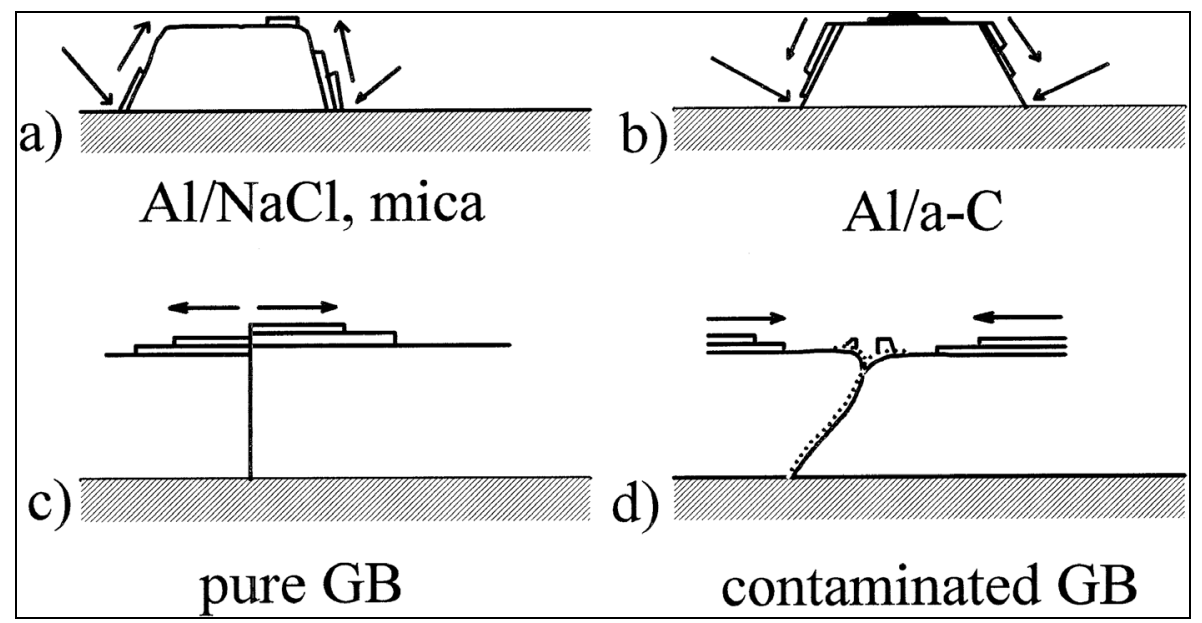

Fig. 8. Types of crystal growth in polycrystalline thin films: $a-$ and b- growth of dispersed individual crystals on the substrate surface, the intersection line between the substrate and the side crystal faces are active (a) and passive (b) in the monolayer nucleation; c- and drole of grain boundaries in the growth of crystals as parts of a polycrystalline matrix, pure grain boundary active in the monolayer nucleation (a), contaminated grain boundary passive in the monolayer nucleation (b). (Barna \& Adamimik)

\section{Influence of the normalized temperature $\left(T_{s} / T_{m}\right)$ on the structure and microstructure of thin films}

The structural behavior, as a function of the normalized temperature of $\mathrm{Ts} / \mathrm{T}_{\mathrm{m}}<0.3$ is shown in Fig. 9. In general, the patterns recorded from the various films grown present the same reflections as the target $(\delta-\mathrm{NbN}$ cubic phase), but show important differences in the relative intensities, in particular those corresponding to planes (111) and (200), which increase with an increase of the absolute temperature. Regarding this, it is important to point out that contrary to what occurs in the target and the rest of the film patterns, the XRD pattern of the film grown at $553 \mathrm{~K}$ shows a greater intensity for the reflection from plane (111) than from that corresponding to the (200) plane. While the (111) plane in the target pattern has a relative intensity of $100 \%$ compared to $86 \%$ for the (200) plane, in the $553 \mathrm{~K}$ sample the relative intensity of the (200) plane is approximately $6 \%$ of the corresponding (111) plane. This result indicates that the supply of additional $22.4 \mathrm{meV}$ to the substrate (which is the energy difference between room temperature and $553 \mathrm{~K}$ ) does not bring about changes in the polycrystalline character of the materials, but gives place to the growth of films with preferred orientation along the (111) plane. 


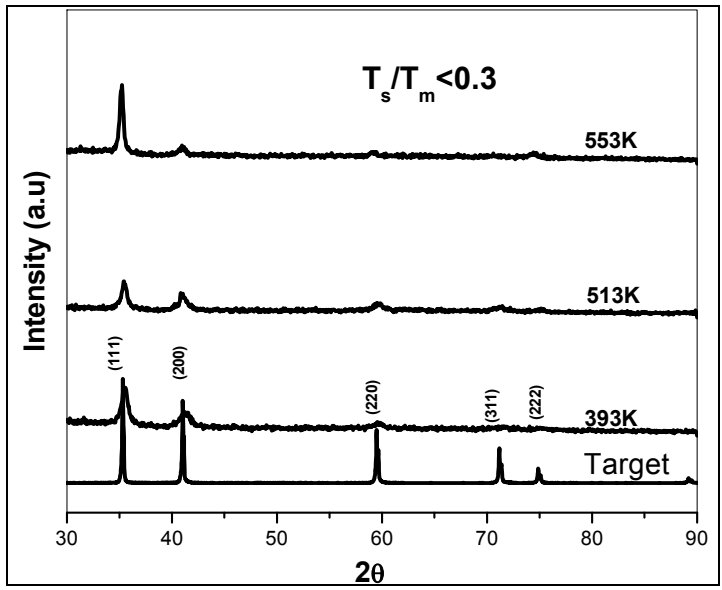

Fig. 9. XRD pattern of $\mathrm{NbN}$ thin films deposited at a normalized temperature $\left(\mathrm{T}_{\mathrm{s}} / \mathrm{T}_{\mathrm{m}}<0.3\right)$ at $300 \mathrm{~W}$ of power.

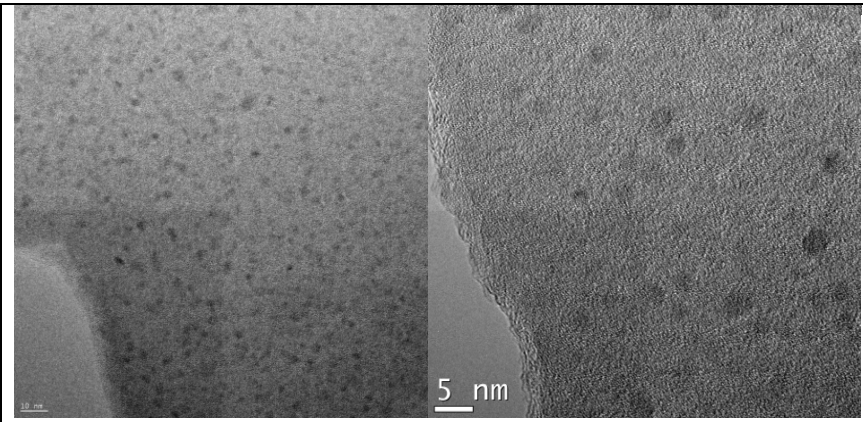

a)

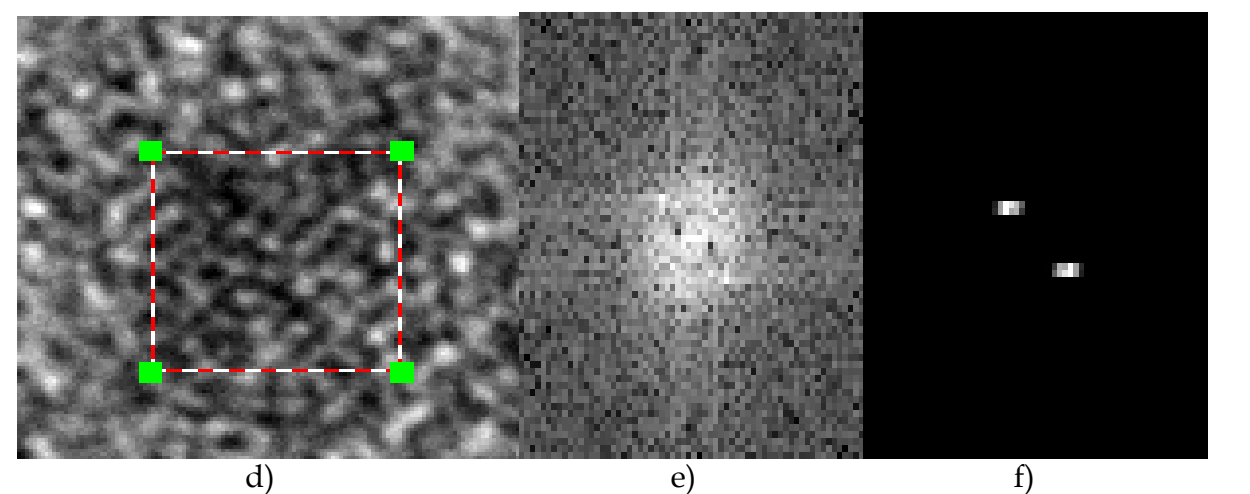

Fig. 10.a) and 10.b) TEM micrographs using multibeam configuration of $\mathrm{NbN}$ nanoparticles distributed homogeneously; c) average grain size of $\mathrm{NbN}$ nanoparticles; d) HRTEM micrographs shows atomic planes; e) reciprocal space of a $\mathrm{NbN}$ nanoparticle; and $\mathrm{f}$ ) distance between (200) planes. 
Fig. 10 shows the micro-structural analysis carried out on the $\mathrm{NbN}$ films through transmission ion electron microcopy (TEM). Micrographs 10a and 10b correspond to the image obtained in multibeam configuration, and in them one can observe an amorphous matrix with crystalline nanoparticles with spherical morphology that are homogenously distributed along the growth plane of the film. Using Gatan software, it was determined that the average grain size of the nanoparticles was $2.7 \pm 0.6 \mathrm{~nm}$ with normal distribution (fig. 10c). When doing magnification of nanoparticles of Fig. 10a, we can observe an interferential pattern produced by the atoms belonging to the $\mathrm{NbN}$ film (fig. $9 \mathrm{~d}$ ). Higher magnifications of the nanoparticles visualized in Fig. 10a let us observe atomic planes as a product of the interferential pattern produced by the arrangement of atoms belonging to the $\mathrm{NbN}$ film (Fig.10d). Image processing of Fig. 10d, using the Fourier transform, lets us visualize the reciprocal space of one $\mathrm{NbN}$ nanoparticle (Fig. 10e). Applying a mask (Fig. 10f) over the corresponding diffracting spots and directly measuring the distance between them $(0.224$ $\mathrm{nm}$ ), we can confirm that they correspond to distances between (200) planes of $\delta-\mathrm{NbN}$. These results confirm the analysis of $\mathrm{XRD}$, which established that $\mathrm{NbN}$ grows preferentially along the (200) plane.

To produce thin films with normalized temperature larger than 0.3 it is necessary to have ultrahigh-vacuum equipment. This condition limits the production the thin films through magnetron sputtering. However, there are studies such as that of Frederick (Frederic \& Gall, 2005), who grew CrN thin films on $\mathrm{MgO}$ substrate through magnetron sputtering with Ts/tm between 0.43 to 0.48 . These authors found that the films grown at $993 \mathrm{~K}$ present complete single-crystal structure with smooth surfaces. The root-mean-square surface roughness for 230-nm-thick layers decreases from 18.8 to 9.3 to $1.1 \mathrm{~nm}$ as Ts is raised from 873 to 973 to $1073 \mathrm{~K}$.

\subsection{Influence of the gas flow on the structure and microstructure of thin films}

In a different set of experiments, nitrogen gas was introduced into the deposition chamber (maintaining the final working pressure constant) in order to study the influence that the addition of this gas during deposition exerts on the structural and micro structural properties of the $\mathrm{NbN}$ films. Fig. 11 shows the diffraction patterns recorded from the films grown at $300 \mathrm{~W}, 553 \mathrm{~K}$ and different nitrogen flows. The results obtained make clear that in all cases a preferential growth appears along the (200) plane (Fig.11a). The relative intensity of this diffraction peak is so high that it makes it impossible to distinguish the diffraction peaks corresponding to other planes. To determine the polycrystalline character of the film, we carried out $X$-ray diffraction experiments at grazing incidence. Fig. $11 \mathrm{~b}$ shows a representative example. It is clear from Fig. 11 that the films show the same diffraction peaks as the target, confirming their polycrystalline character, although having a preferential orientation along the (200) plane (texture index, 0.65). The grain sizes deduced by Scherer's equation (Cullity, 2001) for the different films grown along the (200) plane vary from $35 \mathrm{~nm}(\Phi=2 \mathrm{sscm})$ to $42 \mathrm{~nm}(\Phi=6 \mathrm{sscm})$. These results indicate that incorporation of nitrogen during the fabrication process favors the preferential growth of the $\mathrm{d}-\mathrm{NbN}$ phase along the (200) plane. This effect has also been produced during the growth of TiN films, due to the change of the preferred orientation of the films from the [111] direction to the [200] direction when the gas flow is increased.

The incorporation of nitrogen during the deposition process implies changes in the dynamics of the plasma, since the increase in the number of nitrogen molecules increases the 
probability of collisions, promoting a larger number of chemical reactions on the substrate surface. These reactions can be explained using a model of low energy $(<20 \mathrm{eV})$ ion bombardment during film growth at a Ts/Tm ratio ranging between 0.1 and 0.3 (a condition which is satisfied in this case) (Petrov \& Barna, 2003). According to this model, $25 \mathrm{eV}$ are sufficient to cause collision dissociation of the $\mathrm{N}_{2}$ ions, providing a continuous source of atomic nitrogen. The nitrogen readily chemisorbs on the (200) planes but not on the Nterminated (111) planes. This in turn reduces the mean free path of the metal cation on the (200) plane due to capture by the nitrogen atoms, and promotes the formation of a $\mathrm{NbNi}$

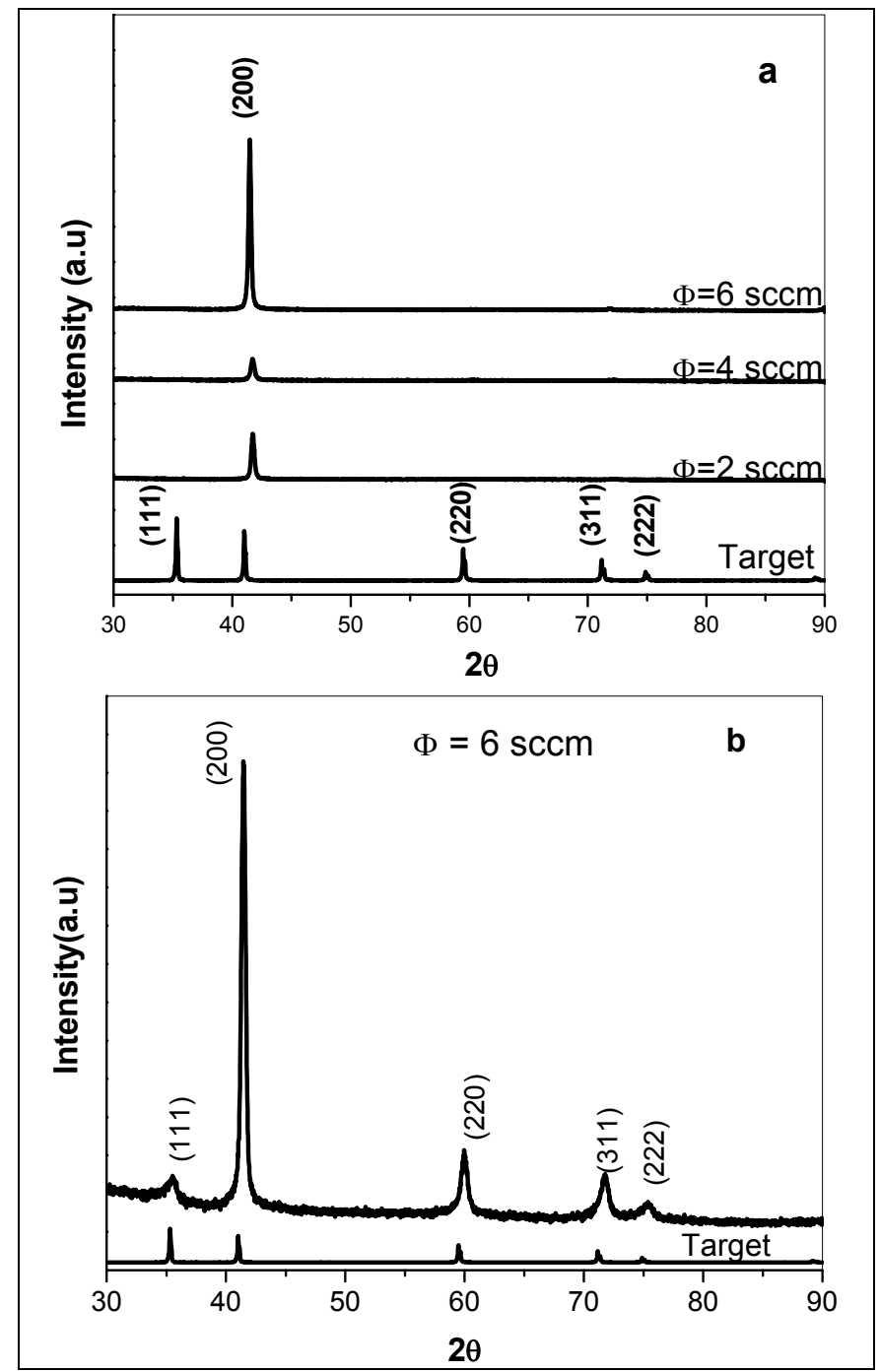

Fig. 11. a) XRD patterns $\theta-2 \theta$ configuration and $b)$ Grazing angle $\left(2^{\circ}\right)$ XRD pattern recorder from the $\mathrm{NbN}$ film, grown at $300 \mathrm{~W}, 553 \mathrm{~K}, 20 \mathrm{sccm}$ of Ar and $6 \mathrm{sccm}$ of $\mathrm{N}_{2}$. 
( $i=1-4)$ admolecule or islands of adatoms (Petrov \& Barna, 2003). This can be considered as causing an additional decrease in the (200) surface energy relative to that of the (111) plane. Consequently, the presence of the nitrogen atoms reduces the flow of cations from the (200) to the (111) planes, resulting in the orientation of the growth along the [200] direction. In this example, the growth of the films depends on the final working pressure as well as the bombardment energy of the ions.

The SEM study (Fig. 12a and 12b) of film growth as a function of the gas flow indicates that the $\mathrm{NbN}$ films present a compact granular structure, with a columnar growth of the type described by Movchan and Demchisshim (Movchan \& Demchisshim, 1969), having an average thickness of $0.7 \mu \mathrm{m}$, which implies a deposition rate of $20 \mathrm{~nm} / \mathrm{min}$.

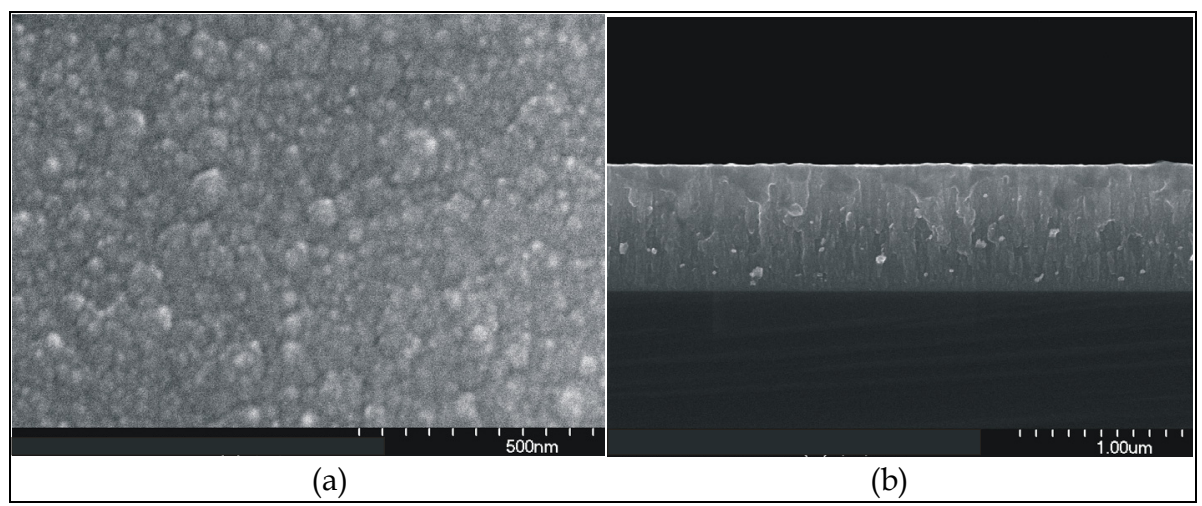

Fig. 12. a) Micrograph of the morphology of $\mathrm{NbN}$ thin film. b) Micrograph of the crosssection of $\mathrm{NbN}$ film, grown at $300 \mathrm{~W}$ and $553 \mathrm{~K}, 20 \mathrm{sccm}$ of Ar and $6 \mathrm{sccm}$ of $\mathrm{N}_{2}$.

An interesting example of the growth of thin films in a reactive phase through the $\mathrm{rf}$ sputtering technique is $\mathrm{ZrN}_{\mathrm{x}} \mathrm{O}_{\mathrm{y}}$ thin films, which grow at different flow ratios $\left(\mathrm{N}_{2} / \mathrm{O}_{2}\right)$, but with the final working pressure constant $\left(7.4 \times 10^{-1} \mathrm{~Pa}\right)$. The results of the XRD studies are shown in figures $13 \mathrm{a}$ and $13 \mathrm{~b}$, where it is possible to observe the influence that the flows have on the crystallographic of the films. Fig. 13a shows the XRD pattern of the films where the nitrogen flow was maintained constant $(2.5 \mathrm{sccm})$ and the oxygen flow was varied, and Fig. $13 \mathrm{~b}$ shows the XRD pattern of the films where the oxygen flow was maintained constant $(2.0 \mathrm{sccm})$ and the nitrogen flow was varied.

The results obtained allowed establishing that there is an optimum flow ratio of 1.25 in which growth of a film with a high degree of crystallinity is reached. This behavior is very similar to the $\mathrm{NbN}$ films discussed above; therefore, the physicochemical mechanisms involved in the growth of thin films are the same for nitrogen molecules as for oxygen molecules, due to the higher reactivity of oxygen as compared to nitrogen (Martin, et al., 2001).

The SEM study (Fig. 14a) of $\mathrm{ZrN}_{\mathrm{x}} \mathrm{O}_{\mathrm{y}}$ films that were grown at a flow ratio of 1.25 present a highly homogenous and maybe very compact surface in which it is not possible to find contrast, and therefore the growth mechanism is not well defined. The microstructure of the 
films was evaluated through AFM studies (Fig. 14b). The micrograph reveals that the average size grain was $150 \mathrm{~nm}$ with an average rugosity of $5.9 \mathrm{~nm}$.

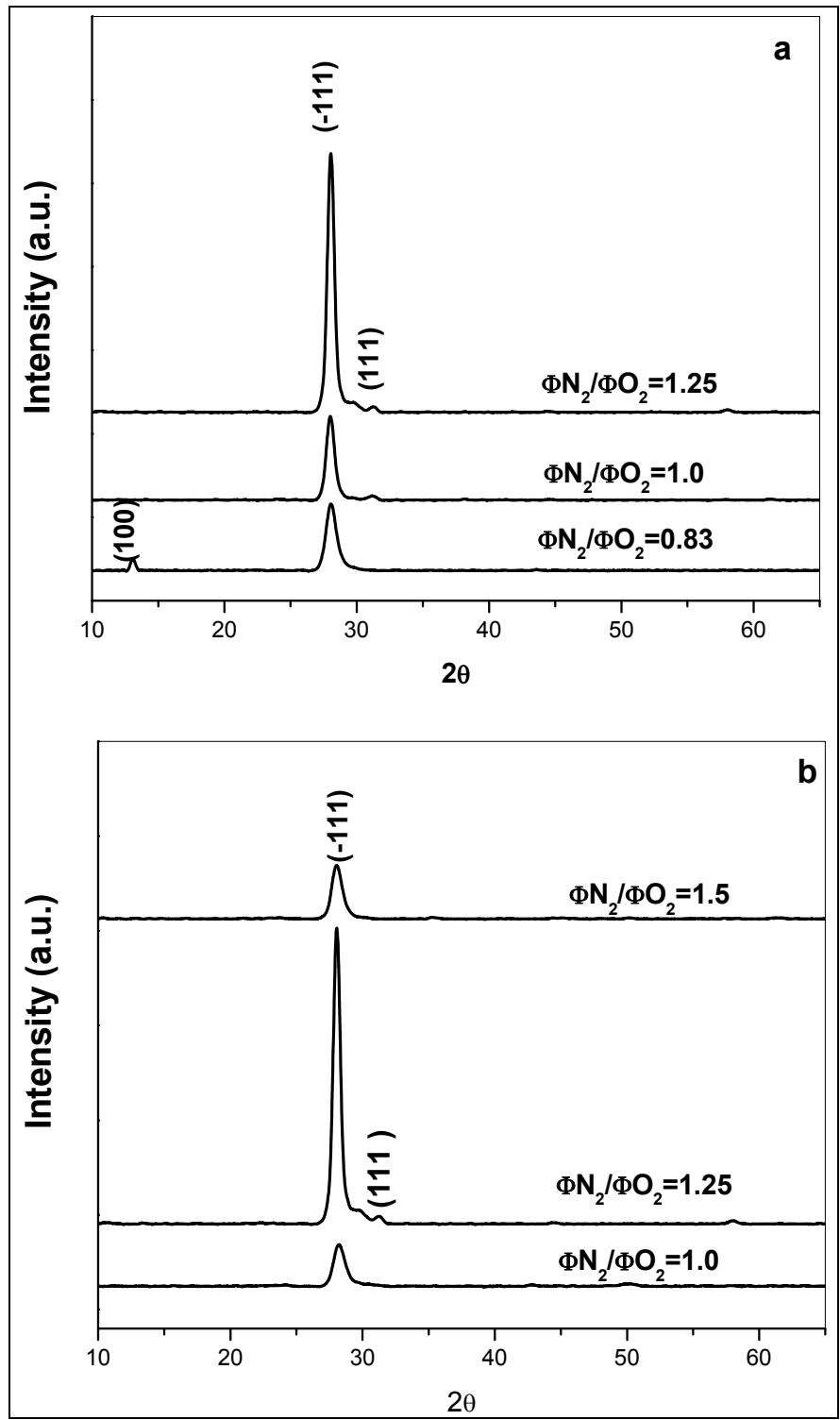

Fig. 13. XRD Patterns recorded from $\mathrm{ZrN}_{\mathrm{x}} \mathrm{O}_{\mathrm{y}}$ thin films deposited on common glass at $623 \mathrm{~K}$ and different ratios flow $\left(\Phi \mathrm{N}_{2} / \Phi \mathrm{O}_{2}\right)$. a- $\Phi \mathrm{N}_{2}$ constant at $2.5 \mathrm{sccm}$ and b- $\Phi \mathrm{O}_{2}$ constant at 2.0 sccm. 


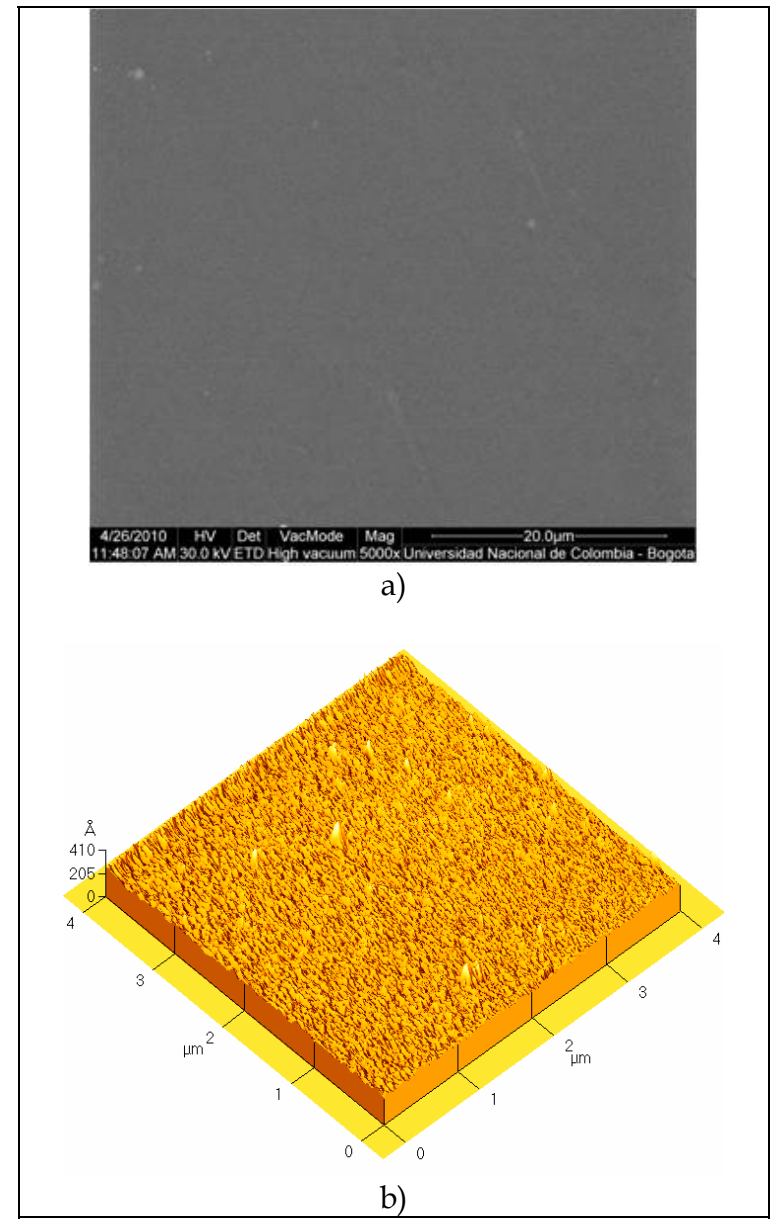

Fig. 14. a- Micrograph of the morphology of $\mathrm{ZrN}_{\mathrm{x}} \mathrm{O}_{\mathrm{y}}$ thin film. b- AFM micrograph of the $\mathrm{ZrN}_{\mathrm{x}} \mathrm{O}_{\mathrm{y}}$ film, deposited at $350 \mathrm{~W}, 623 \mathrm{~K}$ and $\Phi \mathrm{N}_{2} / \Phi \mathrm{O}_{2}=1.25$

\subsection{Influence of the power on the structure and microstructure of thin films}

The XRD patterns of $\mathrm{MgO}$ films (Fig. 15a and 15b) recorded from films grown at room temperature shows the influence which the power supply applied to the target has on the structural behavior of thin films. The films grown within the range from 150 to $200 \mathrm{~W}$ showed amorphous behavior (not shown in the XRD pattern). On the other hand, starting at 250W, all films showed the (200) plane corresponding to magnesium oxide in the FCC phase. In the XRD pattern it can also be observed that the intensity of the (200) plane is so high that it makes it impossible to distinguish the diffraction peaks corresponding to other planes. To determine the polycrystalline character of the film, we carried out X-ray diffraction experiments at grazing incidence. From Fig. 15b it is clear that the films present two main diffraction peaks, (200) and (220), which belong to the target, confirming their polycrystalline character, although showing a preferential orientation along the (200) plane (texture index, 0.85). 
Another example that shows the influence of the power supply applied to the target on the crystallization of the films is the growth of $\mathrm{ZrN}_{\mathrm{x}} \mathrm{O}_{\mathrm{y}}$ thin films; the films were grown from the $\mathrm{Zr}$ target in the reactive phase in an atmosphere of nitrogen and oxygen $\left(\Phi_{\mathrm{N}}=2.5 \mathrm{sccm}, \Phi_{\mathrm{O}}=2.0\right.$ $\mathrm{sccm}$ ). In the XRD pattern of Fig. 16, it is possible to determine that there is a threshold power $(250 \mathrm{~W})$ for producing the crystallization of the film on the substrate. At this power, the film grows with a high degree of crystallization along the (111) plane. This behavior can be explained by the energy model, since increasing the power on the target implies increasing the energy of the ions that are bombarding the substrate and therefore improving the mobility of the adatoms, which produce chemical reactions and atomic grouping along the planes with the higher surface energy, which generates films with a high degree of crystallinity.

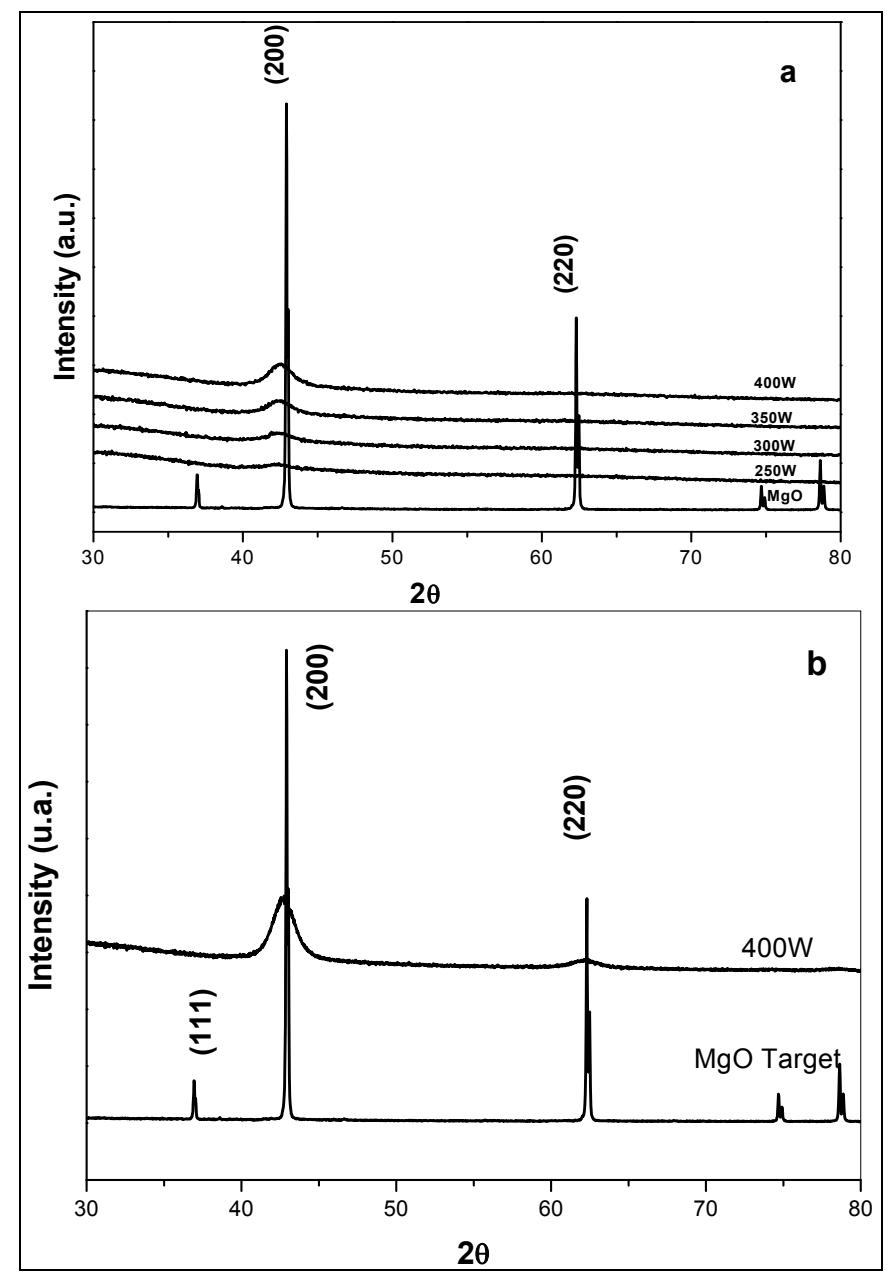

Fig. 15. a- XRD patterns recorded from $\mathrm{MgO}$ films deposited at $293 \mathrm{~K}$ and different power supplies applied to the target $\mathrm{b}$ - Grazing angle $\left(3^{\circ}\right)$ XRD pattern recorded from a $\mathrm{MgO}$ film grown at $400 \mathrm{~W}$. The target XRD pattern is included as reference. 


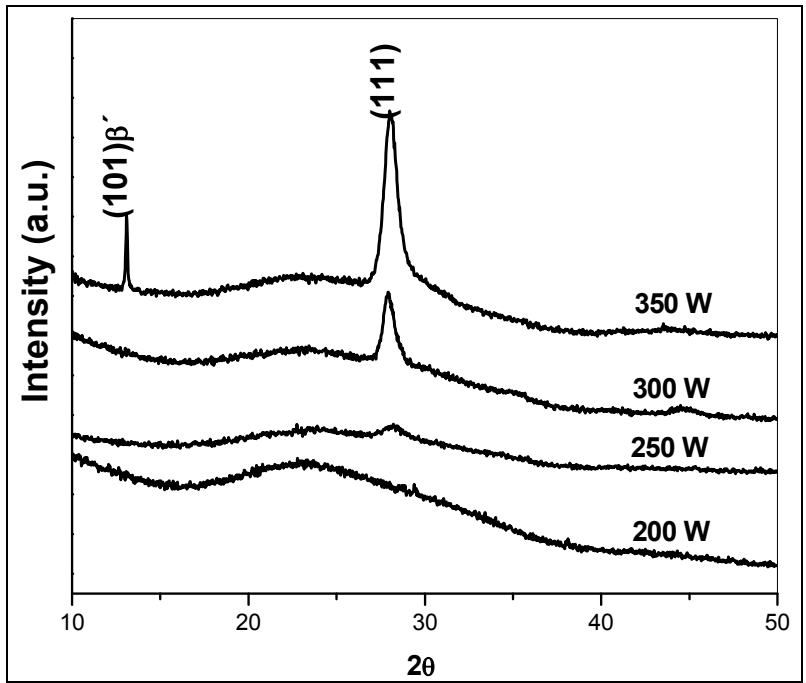

Fig. 16. XRD Patterns recorded from $\mathrm{ZrN}_{\mathrm{x}} \mathrm{O}_{\mathrm{y}}$ thin films deposited on common glass at $623 \mathrm{~K}$ at different powers applied to the target.

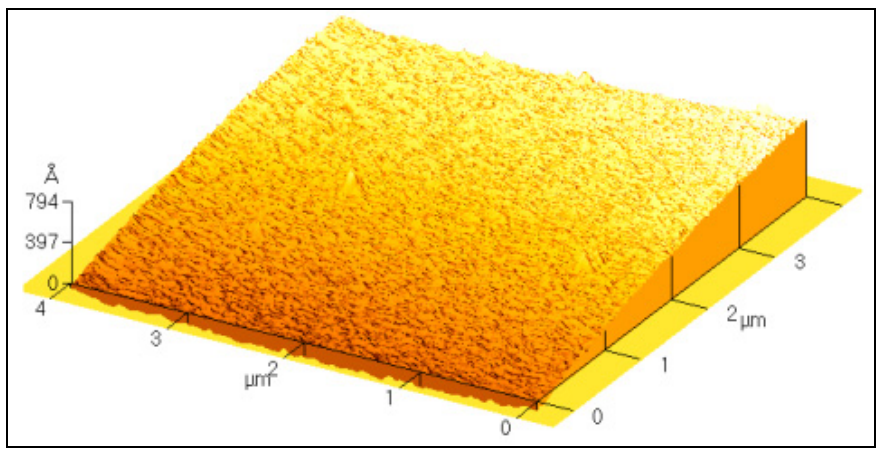

Fig. 17. Atomic force micrographs the $\mathrm{MgO}$ thin films deposited at $400 \mathrm{~W}$.

The study of the microstructure of thin films was carried out using atomic force microscopy (AFM). The micrograph of Fig. 17 shows that in the area swept by the cantilever point $\left(16 \mu \mathrm{m}^{2}\right)$ the film has an average roughness of $20 \mathrm{~nm}$ and an average grain size on the order of $110 \mathrm{~nm}$. These results established that there is a threshold of power for the growth of nano-structured $\mathrm{MgO}$ thin films with high texture without intentional heating of the substrate.

\subsection{Influence of the substrate bias voltage $\left(V_{s}\right)$ on the structure and microstructure of thin films}

Fig. 18 shows the influence that the substrate bias voltage has on the growth of the Ti alloy thin films deposited on steel and glass substrates. The films grown on steel at $-100 \mathrm{~V}$ showed, in addition to the diffraction peaks of the substrate material (note that in all the XRD 
patterns recorded from the films deposited onto steel diffraction peaks from the substrate are still visible), a quite broad peak, which corresponds to the (002) plane of the a- phase of Ti. The XRD pattern corresponding to the films deposited at $-120 \mathrm{~V}$ present two welldefined peaks at $35.1^{\circ}(100)$ and $38.4^{\circ}(110)$, which we associate with the $(\alpha / \beta)$-alloy phase. The film deposited at a bias voltage of $-160 \mathrm{~V}$ shows a peak at $38.4^{\circ}$, which can be associated with the (110) plane of the $\beta$ - phase of Ti. When the bias voltage increases to $-200 \mathrm{~V}$, the XRD pattern shows only one high-intensity peak at $38.4^{\circ}(110)$, which can be associated with the $\beta$ - phase of Ti. It can also be observed that the width of the diffraction peaks is narrower for the films deposited at higher bias voltages, especially for that deposited at $-200 \mathrm{~V}$, which suggests that increasing the bias voltage increases the grain size of the deposited

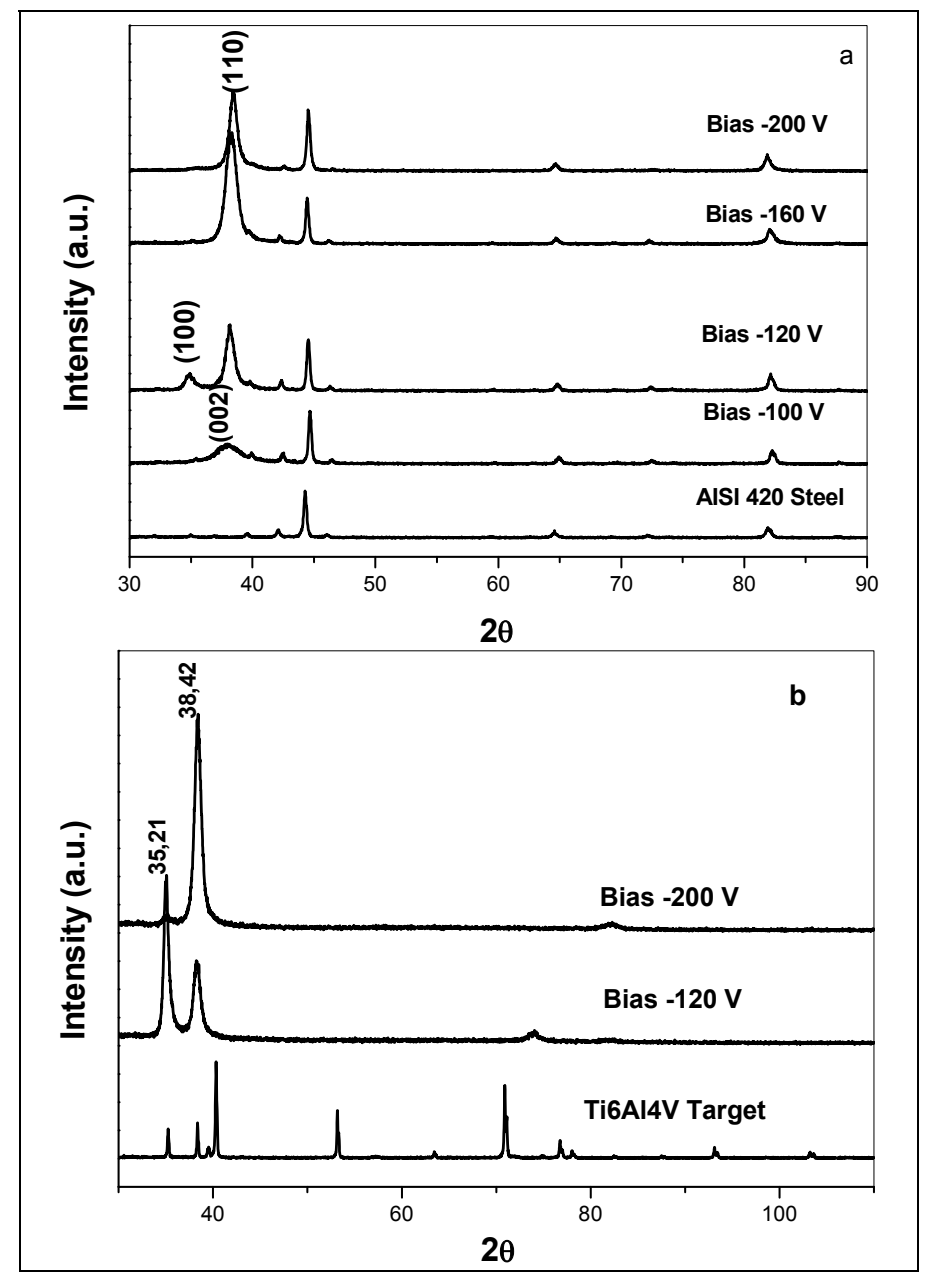

Fig. 18. (a). XRD pattern of the Ti6A14V films deposited by rf magnetron on steel substrates. The substrate appears as a reference. (b) XRD pattern of the films growth on glass and XRD pattern of theTi6A14V in bulk. 
films. The films grown on glass at $120 \mathrm{~V}$ and $-200 \mathrm{~V}$ show a similar behavior, although there are two differences: the two peaks appearing in the XRD pattern of the film grown at $-120 \mathrm{~V}$ show a different intensity ratio from those of the film grown on steel, and the XRD pattern of the film grown at $-200 \mathrm{~V}$ shows an additional low-intensity peak at $82.3^{\circ}$, which we associate with the (220) reflection of the $\beta$-Ti phase.

In summary, it follows from the XRD data that the substrate bias voltage (Vs) has a great influence on the structure of the deposited films: an increase of the bias voltage promotes the growth of different phases of titanium having well-defined different preferential crystallographic orientations. The increase of $\mathrm{V}_{\mathrm{s}}$ is also reflected in a better crystallinity of the deposited films. The data also show that the crystalline phases formed at different $V_{s}$ are the same in both substrates (see fig 18b). These results are in accord with that established in the foregoing section, where it was indicated that the increasing Vs improves the density of the film, which in turn allows obtaining films with a high degree of crystallinity.

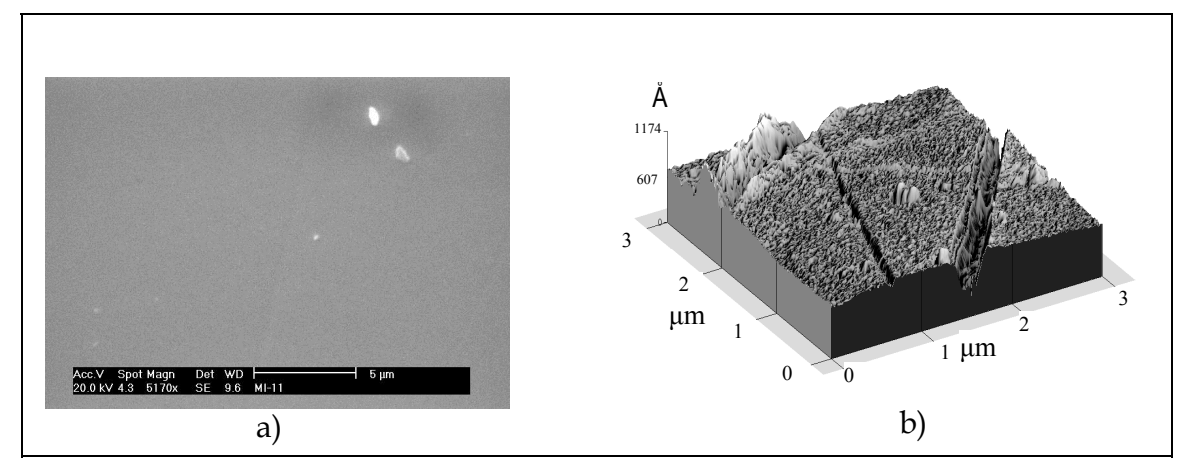

Fig. 19. a) Micrograph of a Ti6A14V film grown on steel with bias voltage of - $200 \mathrm{~V}$. (b) Atomic force Micrograph recorded from Ti6Al4V grown on steel at bias voltage of - 200V.

The analysis of the microstructure of the Ti6Al4V was made through scenic electron microscopy (SEM) and an atomic force microscope (AFM). Fig. 19a shows the SEM results; the recorded micrograph of the film grown at $-200 \mathrm{~V}$ reveals a film with excellent texture, high homogeneity and denser microstructure with grain refinement produced under the enhanced plasma bombardment, which is induced by the substrate bias voltage. Through Scherer's equation (Cullity, 2001) and using the broadening of the (110) and (110) planes of the Ti $\beta$-phase, it was found that the average grain size was $13 \mathrm{~nm}$ for the (100) plane and $16.5 \mathrm{~nm}$ for the (110) plane (Alfonso et al., 2005). Fig. 19b shows the results of the AFM, which indicated that the films grown at $-200 \mathrm{~V}$ possess a roughness of $20 \mathrm{~nm}$ for a scan area of $3 \mu \mathrm{m} \times 3 \mu \mathrm{m}$.

\subsection{Influence of the energy parameter $\left(E_{p}\right)$ on the structure and microstructure of thin films}

The X-ray diffraction patterns of the CrNx films deposited at different Ep values are shown in Fig. 20. It was necessary to use two different scales, because as the Ep increased, the intensity of the $\mathrm{CrN}$ (200) peak increased by two orders of magnitude and became narrower. At Ep values lower than $30 \mathrm{eV} /$ atom, we observed that the films mainly showed a [200] orientation with traces of the CrN[111] and CrN[220] orientations, while at higher Ep values only the CrN[200] 
orientation was detected. An estimation of the $\langle 200\rangle$ texture was obtained comparing the (200) peak intensity (I200) relative to the intensity of all the orientations (Ii) appearing in the XRD pattern. Table 3 summarizes some experimental conditions of the deposition of the $\mathrm{CrN}$ films.

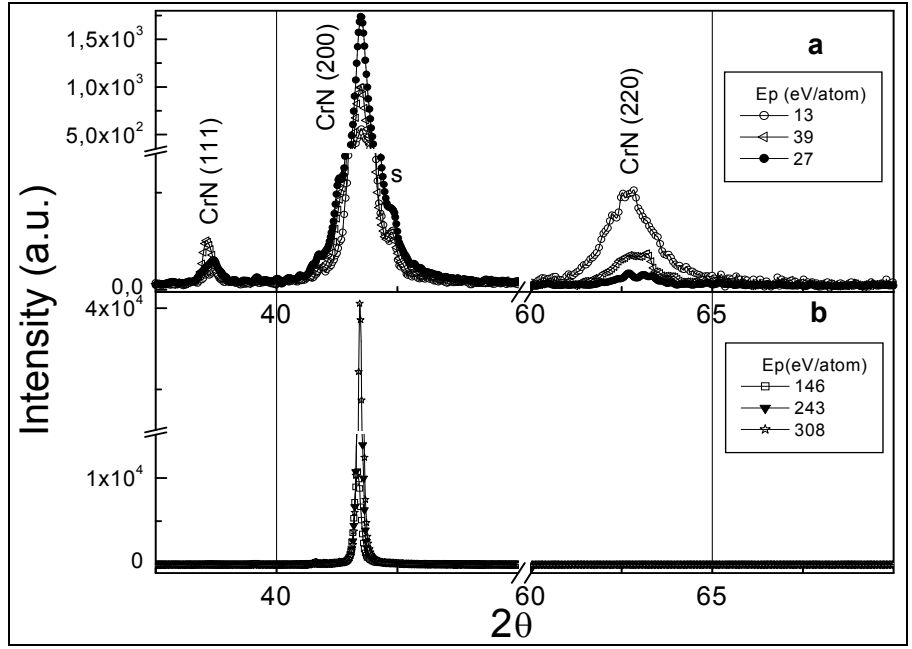

Fig. 20. X-ray diffraction patterns of CrNx coatings: (a) low Ep values, (b) high Ep values.

\begin{tabular}{|c|c|c|c|c|c|c|c|}
\hline Sample & $\begin{array}{c}\mathrm{d} \text { s-t } \\
(\mathrm{cm})\end{array}$ & $\mathrm{Vs}(\mathrm{V})$ & $\begin{array}{c}\mathrm{R} \\
(\mu \mathrm{m} / \mathrm{min})\end{array}$ & $\mathrm{Ei}(\mathrm{eV})$ & $\mathrm{Ji} / \mathrm{Ja}$ & $\begin{array}{c}\mathrm{Ep} \\
(\mathrm{eV} / \mathrm{atom})\end{array}$ & $\mathrm{F}_{<200>}$ \\
\hline CrN-3 & 3 & 0 & 0.10 & 10 & 1.3 & 13 & 0.80 \\
\hline $\mathrm{CrN}-4$ & 4 & 0 & 0.064 & 16 & 2 & 32 & 0.89 \\
\hline CrN-5 & 5 & 0 & 0.051 & 12 & 2.2 & 26 & 0.90 \\
\hline CrN-6 & 6 & 0 & 0.035 & 13.5 & 2.6 & 35 & 0.92 \\
\hline CrN-7 & 7 & 0 & 0.026 & 14.5 & 2.7 & 39 & 0.93 \\
\hline CrN-8 & 8 & 0 & 0.019 & 17 & 2.7 & 46 & 0.92 \\
\hline CrN-3-100 & 3 & -100 & 0.10 & 110 & 1.3 & 143 & 0.99 \\
\hline CrN-4-100 & 4 & -100 & 0.064 & 115.6 & 2.0 & 231 & 0.99 \\
\hline CrN-5-100 & 5 & -100 & 0.05 & 112.3 & 2.2 & 247 & 1.0 \\
\hline CrN-6-100 & 6 & -100 & 0.034 & 113.5 & 2.6 & 295 & 1.0 \\
\hline CrN-7-100 & 7 & -100 & 0.026 & 114.5 & 2.7 & 310 & 1.0 \\
\hline CrN-8-100 & 8 & -100 & 0.019 & 117 & 2.7 & 316 & 1.0 \\
\hline
\end{tabular}

Table 3. Summary of experimental growth conditions of $\mathrm{CrN}$ thin films and some of the results: deposition distance ds-t, r.f. bias voltage Vs, deposition rate R, ion energy Ei, ionatom flow Ji/Ja, energy parameter Ep and texture factor $\mathrm{f}_{<200>}$.

The results of the microstructure behavior of the $\mathrm{CrN}$ thin films are in good agreement with that of the theory of Petrov et al., which was explained above. In the case of CrN thin films, increasing the ion energy by applying a higher substrate bias and keeping low ion-atom flows resulted in a film densification and a change in the preferred orientation from [111] to [002] with a subsequent increase in the levels of stress and the incorporation of argon ions. Moreover, by increasing the energy to around $20 \mathrm{eV}$ and working at higher ion-atom ratios, 
the residual stress remained low, but the texture of the films changed abruptly and completely from the [111] to the [002] direction. According to the Petrov Model, the key factor was that the energy of the $\mathrm{N}_{2}$ ions should be near $20 \mathrm{eV}$ to promote the dissociation of the ions through collision with the film surface, in this way providing a supply of atomic nitrogen which can chemisorb on [002] oriented grains and later capture metal atoms, resulting in the development of the $\langle 002\rangle$ texture. In $\mathrm{CrN}$ films, it was observed that at the lowest Ep values $\left(\mathrm{Ep}<50 \mathrm{eV} /\right.$ atom) with $\mathrm{f}_{(200)} \sim 80 \%$, the film texture was equivalent to the transition regime in Petrov et al.'s research. The ion energy and ion-atom flows were not sufficiently low to produce pure $\langle 111\rangle$ texture, as explained above, but were also not sufficiently high to induce $100 \%\langle 002\rangle$. In this transition regime, a competitive growth between the high-trapping (111) plane and the low surface energy (002) plane was established, since as the ds-t increased, the ion energy of the $\mathrm{N}_{2}$ ions approached $20 \mathrm{eV}$ (see Fig. 20). As the Ep value increased, the conditions favored the formation of the $\langle 002\rangle$ texture. Thus we considered Petrov's theory to be a rather good model to explain the microstructure evolution of the texture in metal nitride films. The competition of the different orientations during growth also affected the microstructure, as observed in Fig. 21a-d. As the ion bombardment increased, the microstructure changed from a non-ordered columnar growth to well-oriented grains that look like fibers coming out from the substrate, i.e. equiaxed grains.

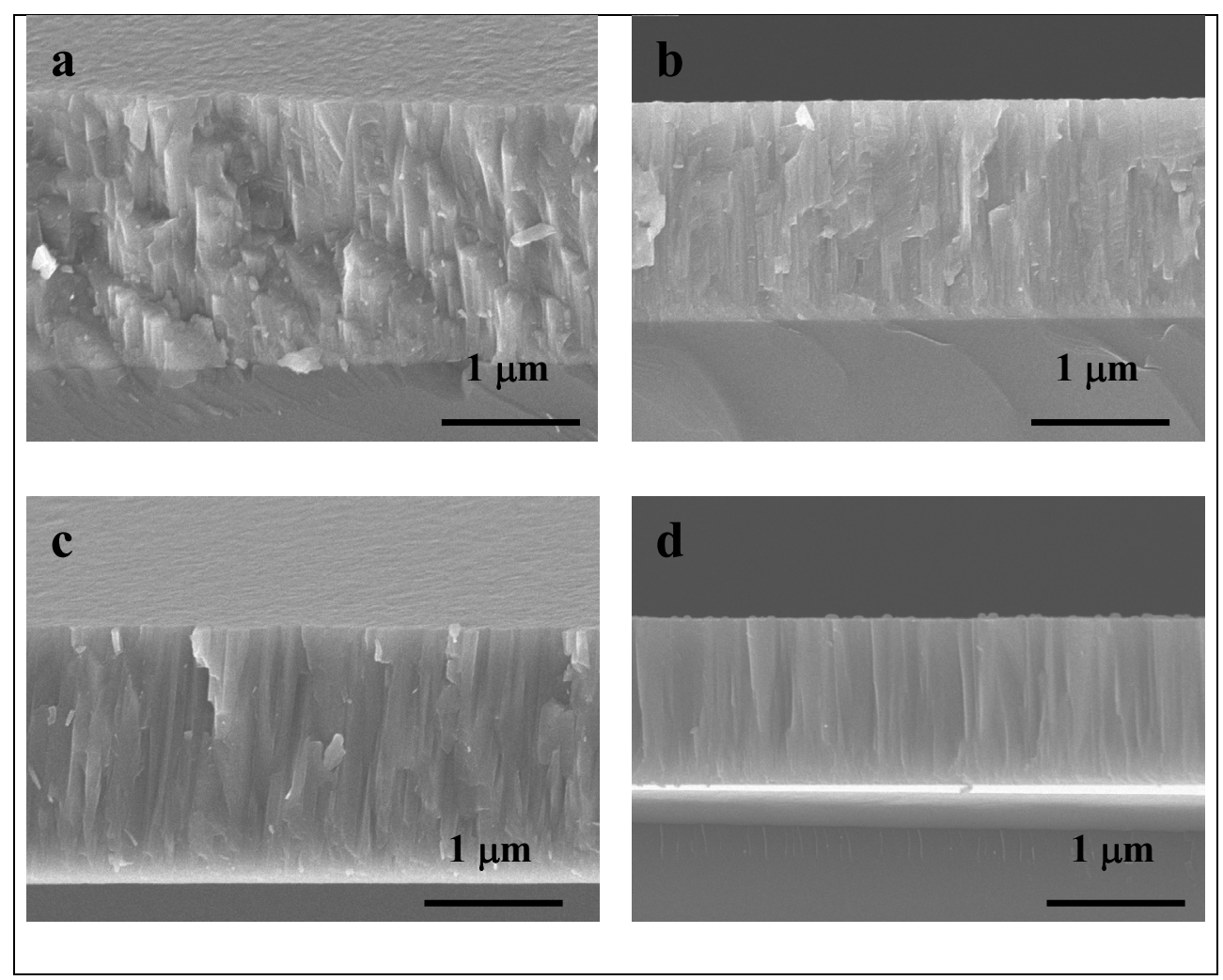

Fig. 21. Cross-section SEM images of samples deposited at increasing Ep values (a) 13, (b) 46, (c) 143 (d) $316 \mathrm{eV} /$ atom, respectively. 


\section{Chemical characterization of thin films}

\subsection{X-ray photoelectron spectroscopy (XPS) analysis}

The last $10 \mathrm{~nm}$ of the surface of thin films can be analyzed using X-ray photoelectron spectroscopy (XPS). As an example, we show the results of XPS on Ti6Al4V thin films. The spontaneously passive film formed on the deposited Ti6Al4V films upon exposure to the air was studied through XPS. Fig. 4 shows high resolution narrow-scan spectra recorded from the Ti $2 p, \mathrm{Al} 2 \mathrm{p}, \mathrm{V} 2 \mathrm{p}$ and $\mathrm{O} 1 \mathrm{~s}$ spectra recorded from one of the samples. All the narrow-scan spectra recorded from the rest of the samples are almost identical to those presented in Fig. 22.
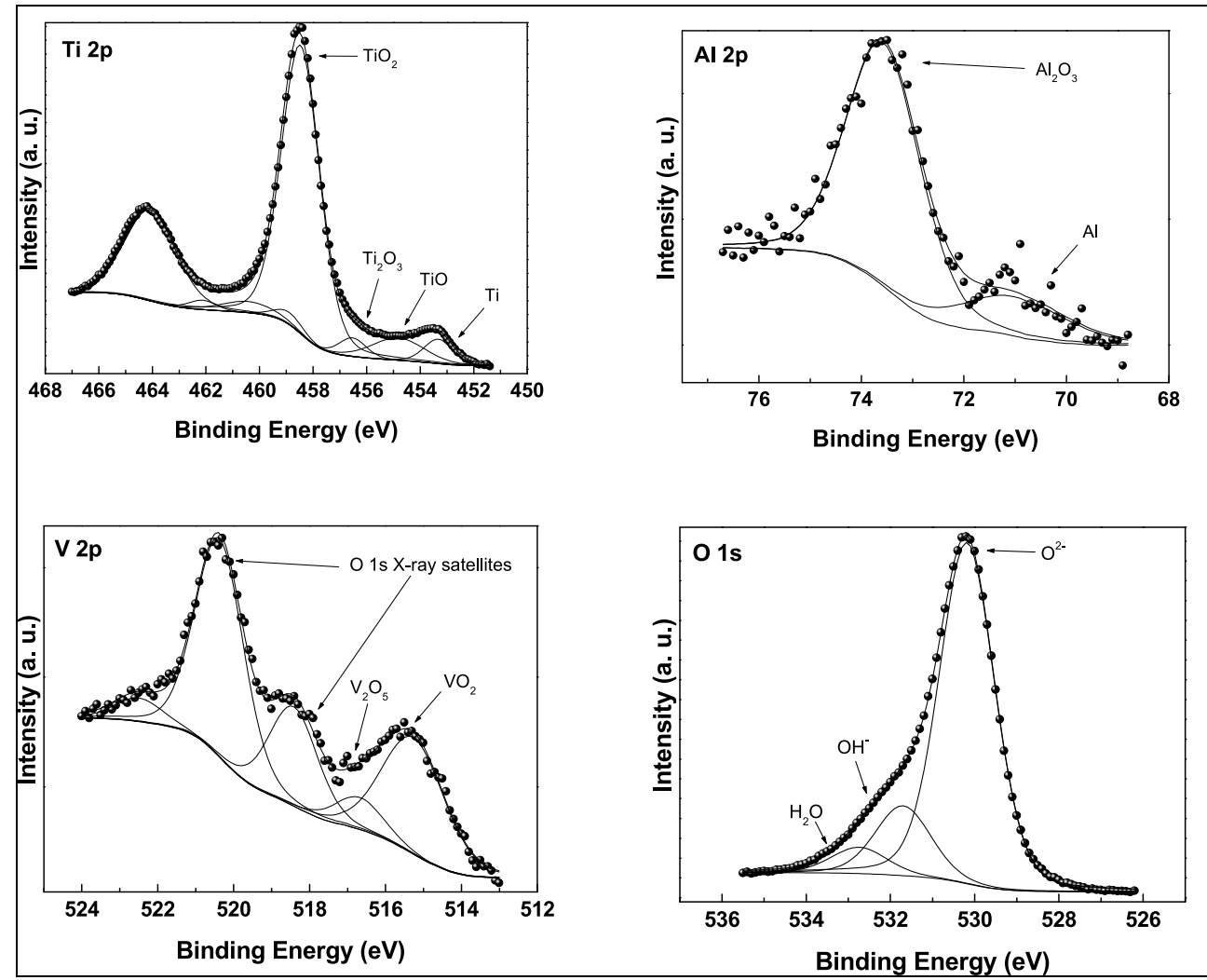

Fig. 22. 2p, Al 2p, V 2p and O 1s XPS narrow-scan spectra recorded from a film deposited at a bias voltage of $-140 \mathrm{~V}$.

The Ti $2 p$ spectrum shows several contributions, and is similar to that reported previously by other authors for the spontaneously-formed passive oxide layer on bulk Ti6Al4V alloy. The spectrum is dominated by a major $\mathrm{TiO}_{2}$ contribution (BE Ti $2 \mathrm{p}_{3 / 2}=458.4 \mathrm{eV}, 82 \%$ ), and shows smaller Ti (BE Ti $\left.2 \mathrm{p}_{3 / 2}=453.3 \mathrm{eV}, 5 \%\right)$, TiO (BE Ti $\left.2 \mathrm{p}_{3 / 2}=454.8 \mathrm{eV}, 9 \%\right)$ and $\mathrm{Ti}_{2} \mathrm{O}_{3}(\mathrm{BE} \mathrm{Ti}$ $2 \mathrm{p}_{3 / 2}=456.5 \mathrm{eV}, 4 \%$ ) contributions. The $\mathrm{Al} 2 \mathrm{p}$ spectrum shows a major $\mathrm{Al}_{2} \mathrm{O}_{3}$ contribution at $73.6 \mathrm{eV}$ and a minor $\mathrm{Al}^{0}$ contribution at $71.0 \mathrm{eV}$. Again this spectrum is similar to that 
observed for the passive oxide layer on a Ti6Al4V alloy. The O 1s peak shows three different contributions: a main one at $530.2 \mathrm{eV}$ that can be associated with metal-oxygen bonds, and two much less intense contributions at $531.7 \mathrm{eV}$ and $532.8 \mathrm{eV}$, which correspond to the presence of $\mathrm{OH}^{-}$groups and chemisorbed water, respectively. The fit of the $\mathrm{V} 2 \mathrm{p}$ spectrum is complicated by the fact that the $\mathrm{V}$ peaks overlap strongly with the $\mathrm{O} 1 \mathrm{~s} \mathrm{~K} \alpha_{3,4} \mathrm{X}$-ray satellite peaks. Therefore, the whole spectrum was refined considering the presence of these satellites and the presence of vanadium peaks. The results show the presence of an intense peak at $515.4 \mathrm{eV}$, which we associate with the presence of $\mathrm{VO}_{2}$, and a less intense vanadium contribution at $516.7 \mathrm{eV}$, which corresponds to $\mathrm{V}_{2} \mathrm{O}_{5}$. This finding contrasts with those of Milosev (Milosev et al., 2000), who did not find oxidized vanadium in the passive layer formed on bulk Ti6Al4V (Alfonso et al., 2006).

These results show that the films that have been grown through rf magnetron sputtering reproduced the stiochoimetry of the target, although on the surface of the thin films chemical reactions will be produced, forming hydroxides and passivation layers.

\subsection{Energy dispersive X-ray (EDX) analysis}

The elemental composition of thin films is determined through energy dispersive X-ray analysis (EDX), although is important to indicate that elements such as oxygen and nitrogen are not possible to assess because the binding energies are very near to the binding energy of the carbon. As an example, the EDX results for $\mathrm{NbN}$ nanoparticle are shown. Fig. 23 shows the elements that constitute the nanoparticles of $\mathrm{NbN}(\mathrm{N}$ and $\mathrm{Nb})$ that formed the $\mathrm{NbN}$ studied in section 4 , and the elements of the substrate (common glass) on which the thin films were grown. The $\mathrm{Cu}$ belongs to the sampling.

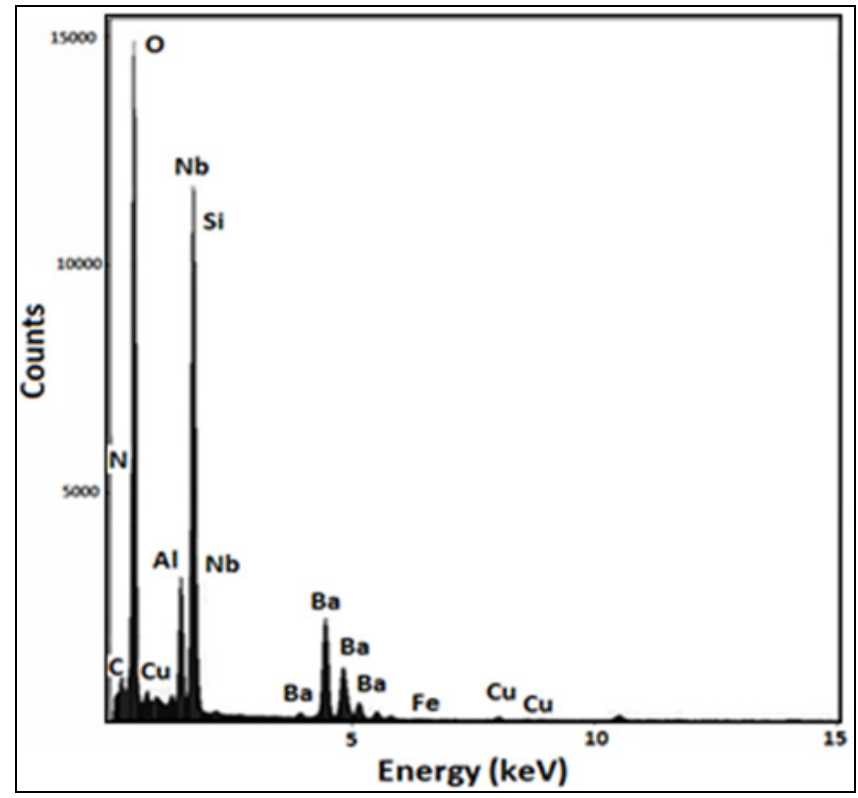

Fig. 23. EDX spectrum of $\mathrm{NbN}$ nanoparticle that integrates the $\mathrm{NbN}$ thin films. 


\section{Optical characterization of thin films}

An important characteristic of thin films is the optical behavior, since this determines possible industrial applications, which range from transparent coatings to optical filters; optical studies are carried out through measurements of transmittance, absorbance and reflectance. Fig. 24 shows the transmittance percent as a function of the wavelength on $\mathrm{MgO}$ thin films that have been grown through rf sputtering with different power supplies applied to the target.

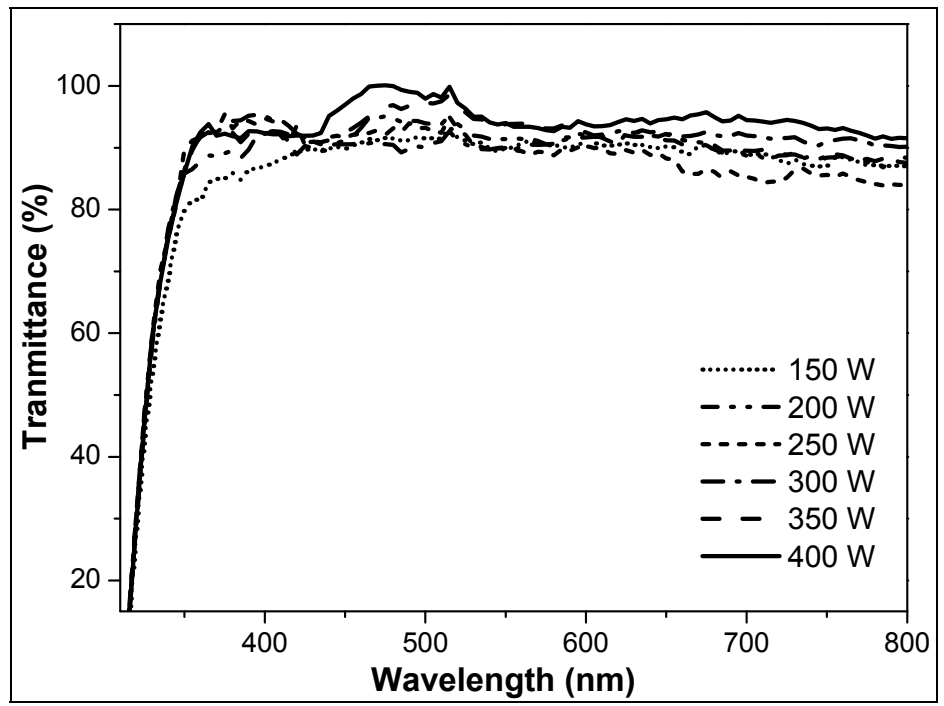

Fig. 24. Transmission spectrum vs wavelength the films the $\mathrm{MgO}$ with various strengths of power supply to the target.

The results show (see Fig. 24) that the films have percentages of transparency that range from $84 \%$ to $95 \%$ in films grown at 150 and $400 \mathrm{~W}$, respectively. These results indicate that films that were grown at a higher power have a high value of transmittance. This behavior is due to the fact that the films are denser and possibly present lower diffraction.

\section{Applications of thin films}

Surface modification by means of thin film deposition is an important industrial process used to protect basic materials against wear, fatigue, corrosion and many other surfacerelated damage phenomena (Vyas et al., 2010; Yang et al., 2008; Wesley, 2001; Li et al., 2009; Kumar, A. \& Kaur, 2009). The modern methods of plasma-assisted physical vapor deposition techniques provide great flexibility for designing films with specific chemistry and microstructure, leading to coatings with unique properties. Among these, ceramic coatings deposited on metallic substrates have shown excellent improvement of the surface properties, such as a low friction coefficient and a high degree of hardness with associated good wear resistance and also corrosion resistance to aggressive environments; (Yang, et al., 2008; Wesley, 2012). 
Films of $\mathrm{CrN}, \mathrm{TiN}, \mathrm{ZrN}, \mathrm{TaN}$ and $\mathrm{NbN}$ were deposited using an unbalanced magnetron sputtering system with different energy parameters to investigate its effect on some film properties. Fig. 23 shows the main results obtained in these films. In general, it may be observed that the residual compressive stresses, determined using the curvature method and Stoney's equation (Stoney, 1909), and increased with the energy parameter, although for some films the variation was very small.

Fig. 25a shows the microhardness of the substrate-film system. Hardness measurements were made on samples deposited on AISI M2 tool steel. The hardness of the substrate was $800 \mathrm{~kg} \mathrm{~mm}^{-2}$. The hardness of the films was 2-3 times higher than the substrate hardness. Group IV nitrides generally are harder than those of group V (Hofmann, 1990). Moreover, the data showed that the hardness increased as the energy parameter increased. This could be attributed to the increase in ion bombardment on the substrate surface, increasing adatom mobility and producing denser films, and the effect on hardness of compressive stresses present in these films (Olaya et al., 2009).

Fig. $25 \mathrm{~b}$ presents the wear coefficient, Kwear, which was evaluated using a ball cratering system, which is a micro scale abrasion test. Two-body grooving abrasion was the wear mechanism observed for all coatings (not shown), probably due to the micro-cutting action of abrasive particles that were dragged across the ball, basically remaining fixed to the ball surface during the test (Adachi, K. \& Hutchings, 2003). The wear coefficients were all in the $10^{-6} \mathrm{~mm}^{3} \mathrm{~N}^{-1} \mathrm{~m}^{-1}$ range, and the lowest values were obtained for $\mathrm{NbN}$ and TaN films. It may be seen that there was a slight decrease in $\mathrm{k}$ wear as the energy parameter increased, but the variation was too small to be considered important. In addition, no clear trend was observed as the unbalance coefficient was increased. This might be a consequence of variations in other film properties, such as the coefficient of friction or the roughness, parameters known to exert a strong influence on the wear performance of the surfaces.

Ceramic films like metallic nitrides on a metal substrate are commonly believed to be immune to corrosion. Fig. $25 \mathrm{c}-\mathrm{d}$ shows the potentiodynamic polarization curves for the films deposited on AISI 304 substrate at the two energy parameters and the AISI 304 substrate in an electrolyte of $0.5 \mathrm{M} \mathrm{H}_{2} \mathrm{SO}_{4}+0.05 \mathrm{M} \mathrm{KSCN}$. The corrosion resistance of a material in the polarization curve is determined by its ability to retain low current densities as the electric potential increases. Quantitatively, Tafel analysis was used to determine the corrosion potential, Ecorr, while the critical passivation current density, Icrit, was estimated from the maximum anodic dissolution current before passivation. The corrosion behavior of PVD ceramic-coated steels in aqueous solutions has been increasingly investigated in recent years (Vyas et al., 2010; Yang et al., 2008; Wesley, 2001; Li et al., 2009; Kumar, A. \& Kaur, 2009). One of the major drawbacks is the presence of defects, which are associated with the growth process in PVD ceramic coatings. These coating defects (e.g. pores) are particularly deleterious for corrosion protection, since they provide direct paths through which the electrolyte can reach the coating/substrate interface, where localized galvanic corrosion occurs due to the difference in the corrosion potential between the coating and the steel. A lot of research has been undertaken to deal with this problem of coating defects (Stansbury\& Buchnan, 2000; Kaciulis et al., 2000; Lang \& Yu, 2001; Lee et al., 2009; Chou \& Huang, 2003) particularly for transition metal nitride coatings, which in general have excellent wear and corrosion resistance and therefore are widely used in industry. 
The critical passivation current density shows that in contrast to the other properties of the films, there was a decrease in the corrosion resistance of the films as the energy parameter increased with Ep. The critical passivation current density is proportional to the exposed area of the substrate due to the existence of pores or pinholes in the film (Olaya et al., 2005). The value of $\mathrm{I}_{\text {crit }}$ depends on the grain limits that join the columns due to the fact that they can contain vacancies, micropores, pinholes, and possibly microcracks, allowing the diffusion of electrolytes of the corrosive solution toward the substrate and increasing degradation of the coatings.

Therefore, the results reported in Fig. $25 \mathrm{c}-\mathrm{d}$ suggest that as the energy parameter increased there was more substrate area exposed at the bottom of the pinholes. These pinholes or defects are usually localized at the grain boundaries, which are defined by the crystal growth process, which consequently models the final film structure. The rise in the corrosion current with Ep was very small for the $\mathrm{NbN}$ and TiN films, but significantly higher for $\mathrm{TaN}, \mathrm{ZrN}$ and $\mathrm{CrN}$. However, the higher ion bombardment induced by the degree of magnetic field created more defects, increasing the residual stresses and therefore deteriorating the film-substrate adhesion and consequently the response of the coatings to the corrosion products, as was visually observed at the end of the corrosion test for the TaN film. This phenomenon can be explained by galvanic coupling produced by a difference in the corrosion potential between coated and uncoated specimens. The potential difference is characterized by anodic dissolution of the substrate material with a high anodic current density at the defect site, leading to an adhesion failure of the coating.

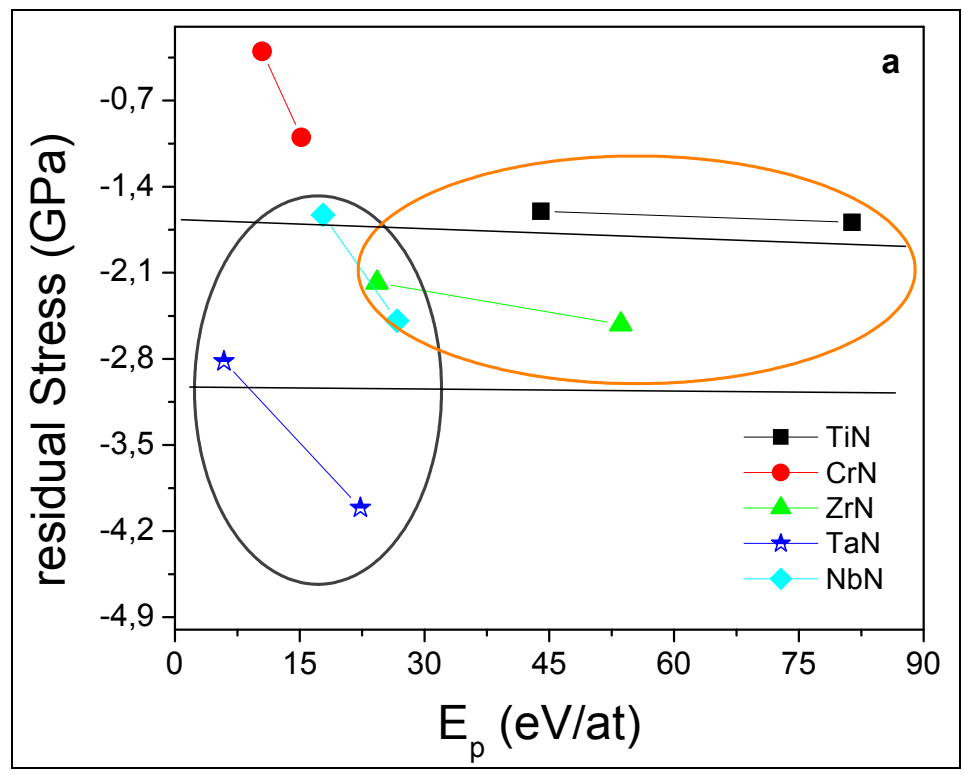




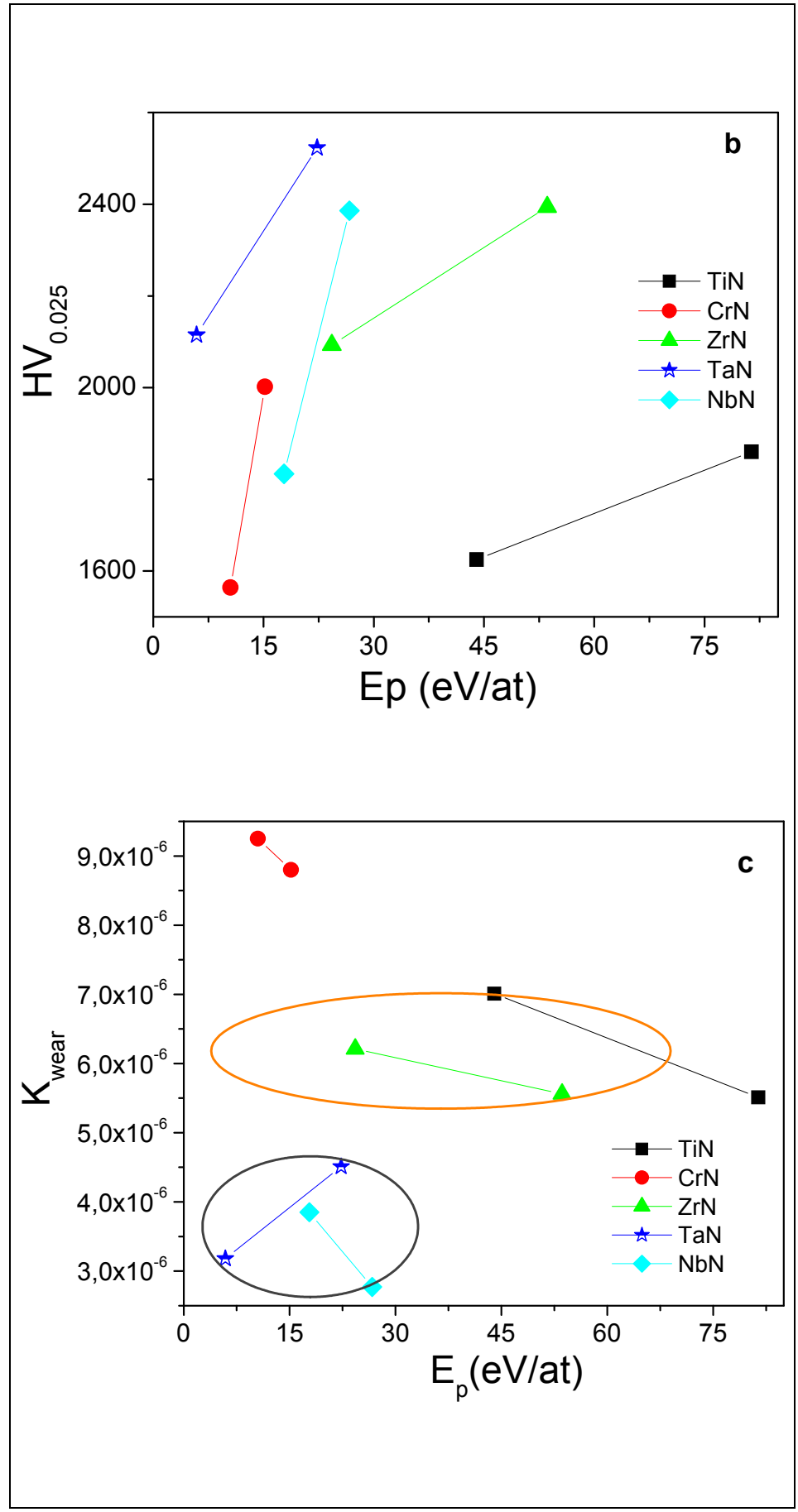




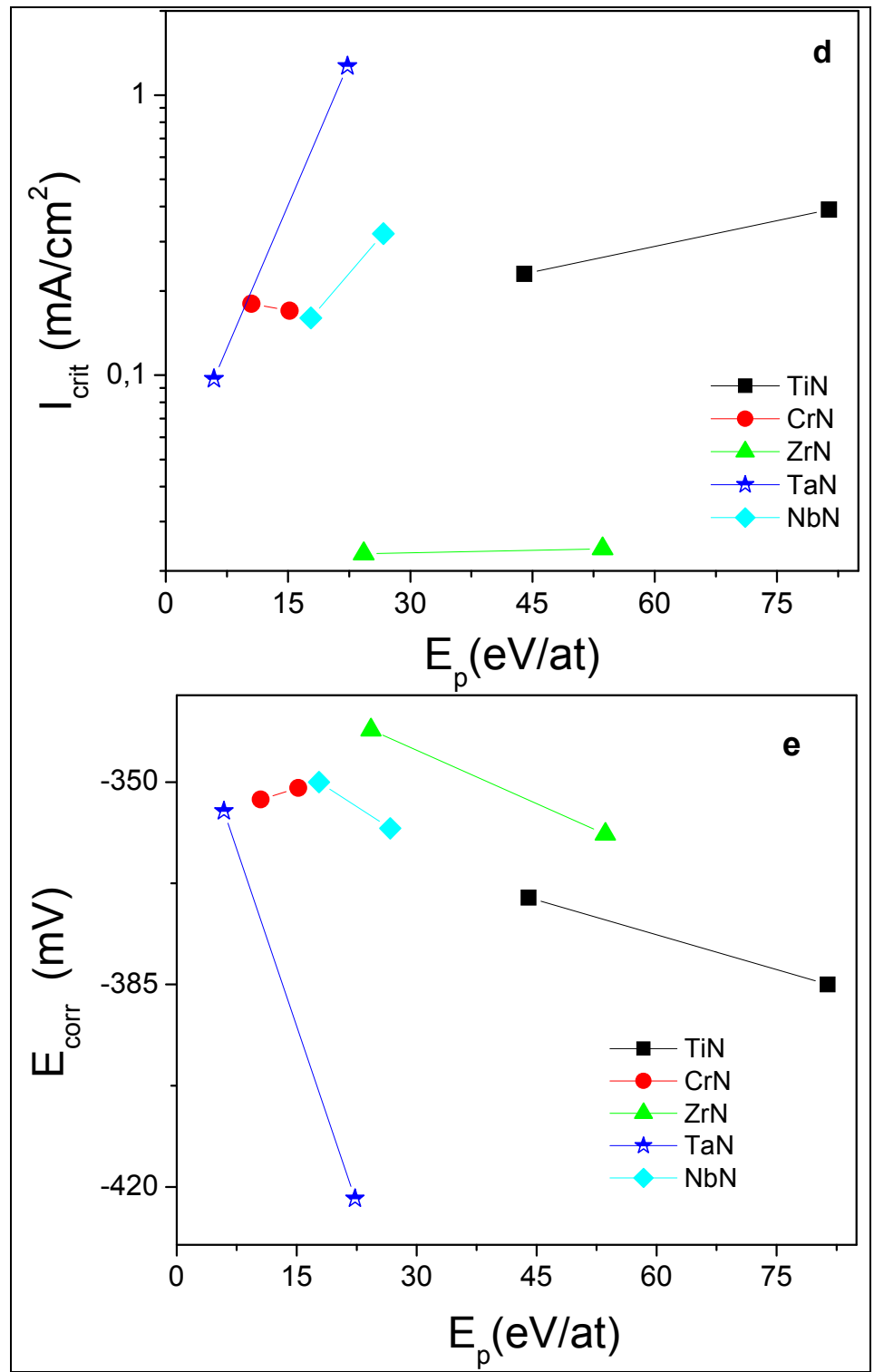

Fig. 25. Summary of mechanical and chemical properties of films deposited through sputtering. a) residual stress b) hardness c) wear coefficient d) critical passivation current and d) corrosion potential

\section{Conclusion}

In this chapter, the main physical-chemical models utilized to explain the growth of thin films through the rf sputtering technique have been presented, and the influence that the 
growth parameters have on the crystallinity and the micro-structure of the thin films has been discussed, and based on the described models, examples have been provided of the thin films' growth under each of the growth parameters. The fundamental idea of presenting these basic theories is to introduce the science of materials to young researchers in the world, helping them to understand by means of examples the basic concepts that apply to the growth of thin films, with the hope that a better understanding of these theories will produce new and better applications.

\section{References}

Adachi, K. \& Hutchings, I., Wear-mode mapping for the micro-scale abrasion test. Wear, Vol 255, issues 1-6, (august-september 2003) 23-29.

B. A. Movchan and A. V. Demchishin, Study of the Structure and Properties of Dioxide thin, Fiz. Met. Metalloved. Vol. 28, (1969) 83-90.

B. D. Cullity, s: R. Stock, Elements of X-ray diffraction, Prentice Hall, 2001.

B. Rauschenbach, J. W. Gerlach, Texture Development in Titanium Nitride Films Grown by Low-Energy Ion Assisted Deposition, Cryst. Res. Technol. Vol. 35, (2000) 6-7.

B. Wang, Y.N. Zhao, Z. He, The effects of deposition parameters on the crystallographic orientation of AIN films prepared by RF reactive sputtering, Vacuum. Vol. 48, (1997) 427-429.

B. Window \& N. Savvides, Charged particle fluxes from planar magnetron sputtering sources, J. Vac. Sci. Technol. A4 (1986) 196-202

Barna, P. , Adamik, M., Fundamental structure forming phenomena of polycrystalline films and the structure zone models. Thin Solid Films, Vol. 317, (April 1998) 27-33.

C. Lin, C. Lee, Growth of Tantalum Nitride Films on Si by Radio Frequency Reactive Sputtering of Ta in N2/ Ar Gas Mixtures: Effect of Bias, J. Electrochem. Soc. Vol. 147, (2000) 713-718.

C. S. Shin, D. Gall, Y. W. Kim, N. Hellgren, I. Petrov, J.E. Greene, Development of preferred orientation in polycrystalline $\mathrm{NaCl}$-structure $\delta$-TaN layers grown by reactive magnetron sputtering: Role of low-energy ion surface interactions, J. Appl. Phys. 92, (2002) 5084.

C.R. Weissmantel, Deposition of Metastable Films by Ion Beam and Plasma Techniques, Proc. 9th Int. Vacuum Congress and 5th Int. Conf. on Solid Surfaces (Madrid), 26 Sept-1 Oct 1983, p 229-308

Chou, W., Yu, G. \& Huang, J. Corrosion resistance of ZrN films on AISI 304 stainless steel substrate. Surface and Coatings Technology. Vol. 167, issue 1, (april 2003) 59-67.

Emery, C., Chourasia,A., Yashar, P., A study of CrNx thin films by X-ray photoelectron spectroscopy J. Elect. Spectros. Relat. Phenom. Vol. 104, issue 1-3, (July 1999) 91-97.

Flores, J. F.; Olaya, J. J.; Colás, R.; Rodil, S. E.; Valdez, B. S.; Fuente, I. G. Corrosion behaviour of TaN thin PVD films on steels. Corrosion Engineering, Science and Tecjnology, Vol. 4, issue 2, (June 2006) 168-176.

G. G. Stoney, The measurement of stress in layered structures, in: Proc. Roy. Soc. London Vol. A82, (1909) 172.

G. Kamath , A.P. Ehiasarian, Y. Purandare, P.Eh. Hovsepian, Tribological and oxidation behaviour of TiAlCN/VCN nanoscale multilayer coating deposited by the combined HIPIMS/(HIPIMS-UBM) technique, Surface \& Coatings Technology 205 (2011) 2823-2829

Goldfarb, I., Pelleg, J., Zevin, L. and Croitoru, N. (1991). Lattice distortion in thin films of IVB metal (Ti, Zr, Hr) Nitrides, Thin Solid Film, Vol. 200, issue 1, (May 1991) 117127., (May 1991), 117-127. 
Greene, J. E., Low Energy Ion Bombardment during Film Deposition from the Vapor Phase: Effects on Microstructure and Microchemistry, Solid State Technol., 30,(4), (1987)115.

Greene, J. E., Nucleation, Film Growth, and Microstructural Evolution, Deposition Processes for Films and Coating, 2nd edition, (R. Bunshah,ed.), Ch. 13, Noyes Publications (1994).

H. Liu, W. Tang, D. Hui, L. Hei, F. Lu. Characterization of (Al, Si)N films deposited by balanced magnetron sputtering, Thin Solid Films, Vol. 517, issue 21, 1 (September 2009) 5988-5993.

H.B. Nie, S.Y. Xu, S.J. Wang, L.P. You, Z. Yang, C.K. Ong, J. Li and T.Y.F. Liew, Structural and electrical properties of tantalum nitride thin films fabricated by using reactive radio-frequency magnetron sputtering, Appl. Phys. A. Mater. Sci. process, Vol. 73 (2001) 229- 236.

Hofmann S., Target and substrate surface reaction kinetics in magnetron sputtering of nitride coatings, Thin Solid Films, Vol. 191, (1990) 335-348.

Hwan-Chul Leea, Guen-Hong Kimb, Soon-Ku Hongc, Ki-Young Leea, Yoon-Joong Yonga, Chang-Hwan Chunb, Jai-Young Leea, Influence of sputtering pressure on the microstructure evolution of AlN thin films prepared by reactive sputtering, Thin Solid Films, Vol. 261, issue 1-2, (1 June 1995) 148-153.

I. Milosev, M. Metikos-Hukovic and H.-H Strehblow, Passive film on orthopaedic TiAlV by X-ray photoelectron, Biomaterials, Vol. 21, (2000), 2103.

J. E. Alfonso, Fernando Pacheco, Alvaro Castro P, J. Torres, Influence of the substrate bias voltaje on the crystallographic structure and mechanical properties of Ti6Al4V coatings, deposited by rf magnetro, Phys. Stat. sol. Vol. 10, (2005) 3786-3789.

J. E. Alfonso, J. Torres, and J. F. Marco,. Influence of the Substrate Bias Voltage on the Crystallographic Structure and Surface Composition of Ti6A14V Thin Films Deposited by rf Magnetron Sputtering, Brazilian Journal of Physics, Vol. 36, issue 3, (September 2006) 994-996.

J. E. Greene, J.-E. Sundgren, L. Hultman, I. Petrov, and D. B. Bergstrom, Development of Preferred Orientation in Polycrystalline TiN Layers Grown by Ultra-High-Vacuum Reactive Magnetron Sputtering, Appl. Phys. Letters, Vol. 67, (1995) 2928.

J. H. Je, D. Y. Noh, H.K. Kim, K.S.Liang, Preferred orientation of TiN films studied by a real time synchrotron x-ray scatteringJ. Appl. Phys. 81, (1997) 6126.

J. Musil, S. Kadlec, Reactive sputtering of TiN films at large substrate to target distances, Vacuum, Vol. 40 (1990) 435.

J. Pelleg, L. Z. Zevin, S. Lungo, Lattice distortion in thin films of IV B metal (Ti, Zr, Hr) nitrides Thin Solid Film, Vol. 197, (1991) 117.

J. R. Frederick, D. Gall, Surface morphological evolution of epitaxial $\mathrm{CrN}(001)$ layers, J. Appl. Phys., Vol. 98, (2005) 054906.

J.A. Heimberg, K.J. Wahl, \& I. L. Singer, Superlow friction behavior of diamond like carbon coatings: Time and speed effects, Applied Physics Letters, Vol. 79, issue 17, (april 2001) 2449-2451.

J.J. Olaya, L. Huerta, S.E. Rodil, R. Escamilla, Superconducting niobium nitride films deposited by unbalanced magnetron sputtering, Thin Solid Films, Volume Vol. 516, issue 23, (1 october 2008) 8768-8773

K. Aso, M. Hayakawa, H. Matsuda, K. Hayashi, W. Ishikawa, On specimen preparation by radio frequency planar magnetron sputtering, J. Vac. Sci. technol. Vol. A4, issue 1, (1986) 19-25.

K. Bewilogua a, G. Bra“uer a, A. Dietz a, J. Ga"bler a, G. Goch (1)b, B. Karpuschewski (1)c, B. Szyszka, Surface technology for automotive engineering, Manufacturing Technology, Vol. 58, (2009) 608-627

K. S. Harsha, Principles of Physical Vapor Deposition of Thin Films, Elsevier, 2005. 
K. Shibahara, S. Nishino, and H. Matsunam, Antiphase-domain-free growth of cubic SiC on Si(100), Appl. Phys. Lett., 50, (1987) 1888.

Kaciulis, S., Mezzi, A., Montesperelli, G. Lamastra, F., Rapone, M. Casadei, F., Valente, T. \& Gusmano, G. Multi-technique study of corrosion resistant $\mathrm{CrN} / \mathrm{Cr} / \mathrm{CrN}$ and $\mathrm{CrN}$ : C coatings. Surface and Coatings Technology, Vol. 201, issue 1-2, 12, (6 september 2006) 313-319.

Kelly,P., Arnell, R., Magnetron sputtering: a review of recent developments and applications. Vacuum, Vol. 56, (September 1999) 159-152.

Kelly,P., Arnell, R., The influence of magnetron configuration on ion current density and deposition rate in a dual unbalanced magnetron sputtering system. Surface and Coatings Technology, Vol. 108-109 (1998) 317-322

Kumar,A. \& Kaur, D., Nanoindentation and corrosion studies of TiN/NiTi thin films for biomedical applications. Surface and Coatings Technology, Vol. 204, issue 6-7, (14 december 2009), 1132-1136.

L. Monroy, J. Olaya, M. Rivera2, A. Ortiz3, G. Santana. Growth study of Y-Ba-Cu-O on buffer layers and different substrates made by ultrasonic spray pyrolysis. Rev. LatinAm. Metal. Mat., Vol. 32 (October 2011) 21-29

Lang, F. \& Yu, Z. Surf. Coat. Technolology, The corrosion resistance and wear resistance of thick TiN coatings deposited by arc ion plating. Surface and Coatings Technology, Vol. 145, issue 1-3, (august 2001) 80-87.

Lee, K., Kim, W., Young, J., Won, S.\& CHOE, H. Effects of TiN film coating on electrochemical behaviors of nanotube formed Ti-xHf alloys. Transactions of Nonferrous Metals Society of China, Vol. 19, issue 4, (august 2009) 857-861.

Lingxia Hang , Y. Yin, Junqi Xu, Optimisation of diamond-like carbon films by unbalanced magnetron sputtering for infrared transmission enhancement, Thin Solid Films, Volume 515, Issue 1, (25 September 2006) 357-361.

M. Ishihara, S. J. Li, H. Yumoto, K. Akashi, Y. Ide, Control of preferential orientation of AlN films prepared by the reactive sputtering method Thin Solid Films, Vol. 316 (1998) 152.

M. Marlo, V. Milman, Density- functional study of bulk and surface properties of titanium nitride using different exchange-correlation functional, Physical Review B, Vol. 63, Num. 4 ( January 2000), pp. 2899-2907

Martin, O. Banakh, A.M.E. Santo, S. Springer, R. Sanjines, J. Takadoum, F. Levy, Appl. Surf. Sci. Vol. 185 (2001) 123-133.

Mayrhofer,P., Tischler, G., Mitterer, C., Microstructure and mechanical/thermal properties of $\mathrm{Cr}-\mathrm{N}$ coatings deposited by reactive unbalanced magnetron sputtering, Surf. Coat. Technol. Vol.142-144, (July 2001), 78-84.

Messier, R., Giri, A.P., Roy, R.A., Revised structure zone model for thin film physical structure. Journal of Vacuum Science and Technology, A: Vacuum, Surfaces, and Films, 2(2, Pt. 1), 500-3 .

Mitsunori Kobayashi, Yoshihiko Doi, TiN and TiC coating on cemented carbides by ion plating, Thin Solid Films, Vol. 54, Issue 1, 2, (October 1978) 67-74

Olaya, J., Rodil, S., Muhl, S. \& Sánchez, E. Comparative study of chromium nitride coatings deposited by unbalanced and balanced magnetron sputtering. Thin Solid Films, Vol. 474, issues 1-2, (march 2005), 119-126.

Olaya, J., Rodil,S., Marulanda, D \& B. Bhushan, Propiedades mecánicas de nitruros metálicos depositados con UBM: tecnología eficiente y ambientalmente limpia. Revista Mexicana de física. , Vol.55, issue 6 (november 2009), 425-431.

P. Losbichler, C. Mitterer, Non-reactively sputtered TiN and TiB2 films: influence of activation energy on film growth, Surf. Coat. Technol. Vol. 97, (1997) 567. 
P. Ziemann, E. Kay, Correlation between the ion bombardment during film growth of films and their structure and electrical properties J. Vac. Sci. Technol., A, Vac. Surf. Films, 1 (1983) 512.

P.B. Barna, M. Adamik, in: F.C. Matacotta, G. Ottaviani Eds., Science and Technology of Thin Films World Scientific Publ., Singapore, 1995.

P.B. Barna, M. Adamik,Fundamental structure forming phenomena of polycrystalline films and the structure zone models., Thin Solid Films, 317, (208) 27-33.

Pavel Souček, Tereza Schmidtová, Evaluation of composition, mechanical properties and structure of NC-TiC/a-C:H coatings prepared by balanced magnetron sputtering, Surface and Coatings Technology, In Press, Accepted Manuscript, Available online 16 September 2011.

Petrov,I, Barna, P, Hultman,L, Greene,J., Microstructural evolution during film growth. J. Vac. Sci. Technol. A, Vol 21, No 5, (September 2003), 117-128.

Raymond Constantin, Performance of hard coatings, made by balanced and unbalanced magnetron sputtering, for decorative applications Baham Miremad, Surface and Coatings Technology, Vol. 120-121, (November 1999) 728-733.

René Olivares-Navarrete, Jhon Jairo Olaya, Claudia Ramirez and Sandra Elizabeth Rodil, Coatings 1 (2011) 72-87 G. Ramírez, S.E. Rodil, H. Arzate, S. Muhl, J.J. Olaya Biocompatibility of Niobium coatings, Applied Surface Science, Vol. 257, (2011) 2555-2559

S.E. Rodil and J. J Olaya, Unbalanced magnetic field configuration: plasma and film properties, Journal of Physics: Condensed Matter, Vol. 18,. 1703-1720, 2006.

Siegwart, R. (2001), Indirect Manipulation of a Sphere on a Flat Disk Using Force Information. International Journal of Advanced Robotic Systems, Vol.6, No.4, (December 2009),12-16.

Stansbury E. and Buchnan R. Fundamentals of Electrochemical Corrosion. First edition. ASM International). ISBN 0-87170-676-8, United States of America(2000).

Stefan Wrehde, Marion Quaas, Robert Bogdanowicz, Hartmut Steffen, Harm Wulff, Rainer Hippler, Optical and chemical characterization of thin TiNx films deposited by DCmagnetron sputtering, Vacuum, Vol. 82, (2008) 1115-1119

T. Q. Li, S. Noda, Y. Tsuji, T. Osawa, and H. Komiyama, J. Vac. Sci. Technol. Vol. A 20 (3), (2002) 583-588.

Teer D.G. A , magnetron sputter ion-plating system, Surf Coat Technol, Vol. 39-40, (1989) 565.

Thornton, J., Influence of apparatus geometry and deposition conditions on the structure and topography of thick sputtered coating, J. Vac. Sci. Technol., Vol. 11, (1974) 666-670.

W. Ensinger, Tribological behavior of duplex coating improved by ion implantation, Surf. Coat. Technol. Vol. 99, (1998) 1

W.F. Liu, S. Suzuki, K. Machida, Magnetic properties of Nd-Fe-B film magnets prepared by RF sputtering, Journal of Magnetism and Magnetic Materials, Vol. 308, Issue 1, (January 2007) 126-130.

Waits R.K. J Planar magnetron sputtering, Vac. Sci. Technol. Vol. 15, Issue 2, (1978) 179-87.

Window B, Savvides N, Unbalanced dc magnetron as source high ion flux, J Vac. Sci. Technol. Vol. A 4, Issue 2 (1986) 453-456.

Y. Ochiai, K. Aso, M. Hayakawa, H. Matsuda, K. Hayashi, W. Ishikawa, On specimen preparation by radio frequency planar magnetron sputtering, J. Vac. Sci. technol. Vol. A4, Issue 1, (1986) 19-25

Y.H. Cheng, B.K. Tay, S.P. Lan, Influence of deposition temperature on the structure and internal stress of TiN films deposited by filtered cathodic vacuum arc, J. Vac. Sci. Technol. Vol. A 20, (2002) 1270. 
(C) 2012 The Author(s). Licensee IntechOpen. This is an open access article distributed under the terms of the Creative Commons Attribution 3.0 License, which permits unrestricted use, distribution, and reproduction in any medium, provided the original work is properly cited. 